Franziska Klaucke, Christian Hoffmann, Mathias Hofmann, George Tsatsaronis

\title{
Impact of the chlorine value chain on the demand response potential of the chloralkali process
}

Journal article | Accepted manuscript (Postprint)

This version is available at https://doi.org/10.14279/depositonce-10633

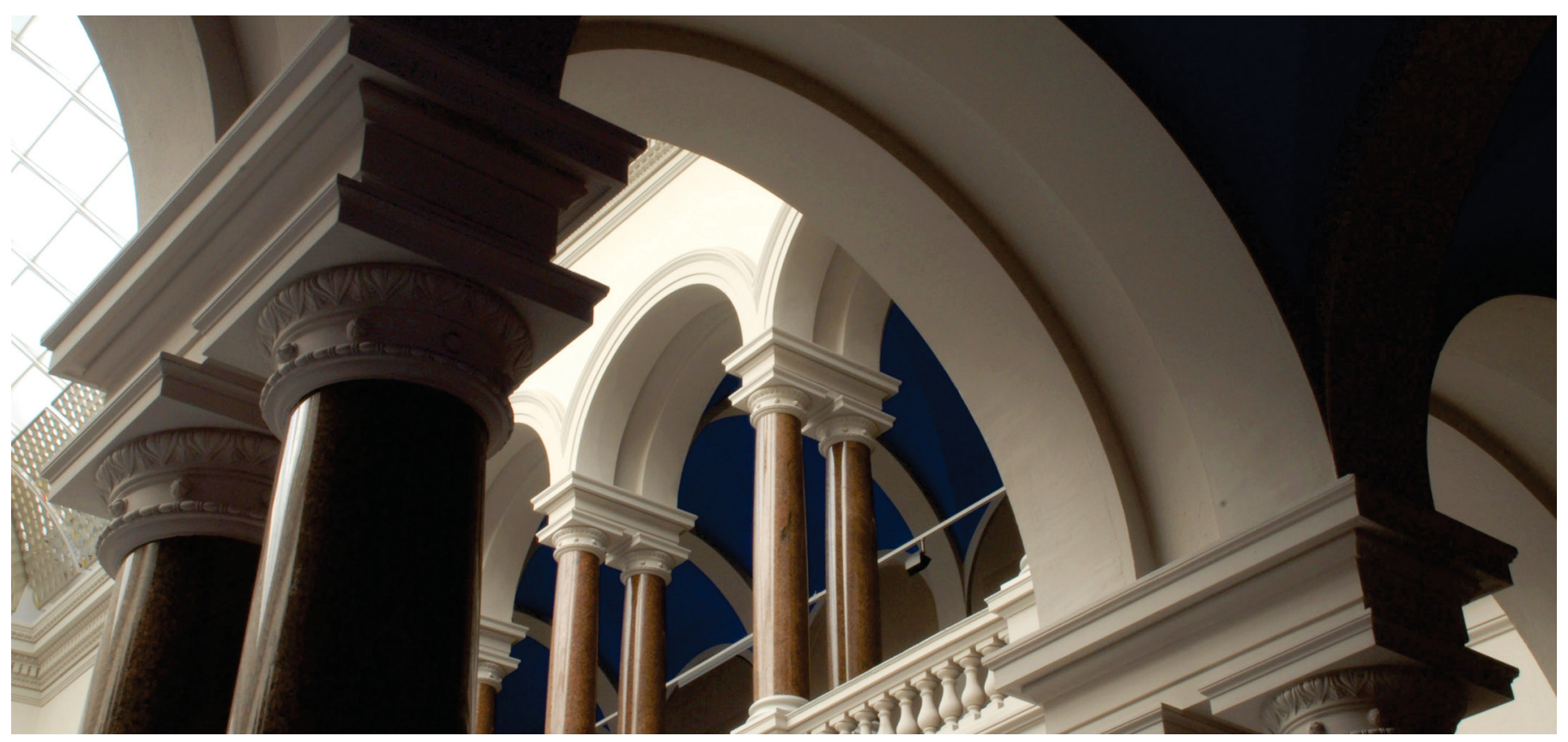

Klaucke, F., Hoffmann, C., Hofmann, M., \& Tsatsaronis, G. (2020). Impact of the chlorine value chain on the demand response potential of the chloralkali process. Applied Energy, 276, 115366.

https://doi.org/10.1016/j.apenergy.2020.115366 


\title{
Impact of the chlorine value chain on the demand response potential of the chloralkali process ${ }^{\text {th }}$
}

\author{
Franziska Klaucke ${ }^{\mathrm{a}, *}$, Christian Hoffmann ${ }^{\mathrm{b}}$, Mathias Hofmann ${ }^{\mathrm{a}}$, George Tsatsaronis ${ }^{\mathrm{a}}$ \\ ${ }^{a}$ Technische Universität Berlin, Chair of Energy Engineering and Environmental Protection, Marchstraße 18, \\ 10587 Berlin, Germany \\ ${ }^{b}$ Technische Universität Berlin, Process Dynamics and Operations Group, Straße des 17. Juni 135, 10623 \\ Berlin, Germany
}

\begin{abstract}
Renewable sources of energy supply an increasing share to the electricity mix although they show much more fluctuations than conventional energy sources. Hence, net stability and availability represent very large challenges. Demand response can positively contribute to the solution of this issue as large electricity consumers adapt their consumption to the available electricity. In the past, chloralkali electrolysis has been suggested as such a large consumer. Unfortunately, its main product, chlorine, cannot be easily stored in large amounts, so that downstream processes have to operate based on a fluctuating feed. This work reviews the processes within the chlorine value chain, determines the most promising ones for flexibilisation based on their chlorine consumption, and analyses these processes in more detail to assign them to one of four flexibility categories. It is shown that $45 \%$ of the theoretical potential could be used for demand response right away.
\end{abstract}

\section{Highlights:}

- A novel approach to evaluate the flexibility of chemical processes is proposed.

- The flexibility potential of the whole chlorine value chain is assessed.

- The chlorine-consuming processes relevant for demand response are identified.

- Subsequent processes limit demand response potential of chloralkali process.

- The dichloroethane and the chloroacetic acid route have the highest potential.

Keywords: Demand response, Flexibility potential, Chloralkali process, Chlorine value chain, Demand side management

\footnotetext{
This is the Accepted Manuscript of: Klaucke, F., Hoffmann, C., Hofmann, M., \& Tsatsaronis, G. (2020). Impact of the chlorine value chain on the demand response potential of the chloralkali process. Applied Energy, 276, 115366. https://doi.org/10.1016/j.apenergy.2020.115366 (C) 2020. This manuscript version is made available under the CC-BY-NC-ND 4.0 license http://creativecommons.org/licenses/by-nc-nd/4.0/

*Corresponding author

Email addresses: franziska.klaucke@tu-berlin.de (Franziska Klaucke), c.hoffmann@tu-berlin.de (Christian Hoffmann), hofmann@iet.tu-berlin.de (Mathias Hofmann), georgios.tsatsaronis@tu-berlin.de (George Tsatsaronis)
} 


\section{Introduction}

The increasing installed capacity of fluctuating renewables in the electricity generation system, alongside the electrification of transport and heating, result in major changes for the energy supply. More flexibility and storage capacity is required to meet the challenges for system reliability [1]. Demand response (DR) is one way for balancing the system [2, 3, 4, The improvement of the modelling approaches of DR on the system level requires a deep knowledge of the potential of the manifold response of demand from highly diverse sectors and applications [5].

The U.S. Department of Energy defines DR as 'changes in electric usage by end-use customers from their normal consumption patterns in response to changes in the price of electricity over time, or to incentive payments designed to induce lower electricity use at times of high wholesale market prices or when system reliability is jeopardized' [6]. The integration of DR activities into an energy system with relevant shares of fluctuating renewables leads to a cost reduction of around $20 \%$ and an increase of more than $10 \%$ of the energy supply from fluctuating renewables assuming the presence of necessary storage capacities [7]. If the electrical demand is higher than the generation, the DR supplier reduces the power consumption. Conversely, if the generation of electricity is higher than the demand, the system will require an increase in the power consumption of the DR supplier. The DR supplier has two options for load reduction with an associated reduced production. One is to catch up the production later. This is called load shift and typically necessitates product storage. The other option is load relinquishment. Here, the loss in production is not made up for later, which leads to lost profits [8]. The potentials for load increase are generally lower than for load decrease, because processes typically operate close to their maximum capacity [9].

Energy-intensive processes are particularly relevant for DR [10]. In contrast to the tertiary and residential sectors with many small and distributed DR potentials, the energy-intensive industrial sector has large, concentrated facilities whose load is almost constant over the year [11].

\subsection{Chloralkali electrolysis}

Chloralkali electrolysis (CAE) accounts for $2 \%$ of the German electricity consumption [9]. This is the largest share of a single branch in the chemical industry. Furthermore, various analyses identified relevant DR potential for the CAE, e.g. [11, 12, and reviewed in [13]. Hence, CAE has significant importance for DR. The three main methods for chlorine production are mercury, diaphragm, and membrane cell electrolysis [14]. In recent years, the membrane technology has become the preferred process in Europe, with a share of over $83 \%$ of the chlorine production in the EU 27 and EFTA countries of 2018 [15]. For this reason, it is treated as the state-of-the-art technology and we will focus here on it.

CAE produces chlorine, sodium hydroxide and hydrogen by electrolysis of pre-treated ultrapure brine [14] as shown simplified in Fig. 1 for the membrane technology. The brine is fed to the anolyte [16]. The cation-exchange membrane separates the anolyte (left) from the 


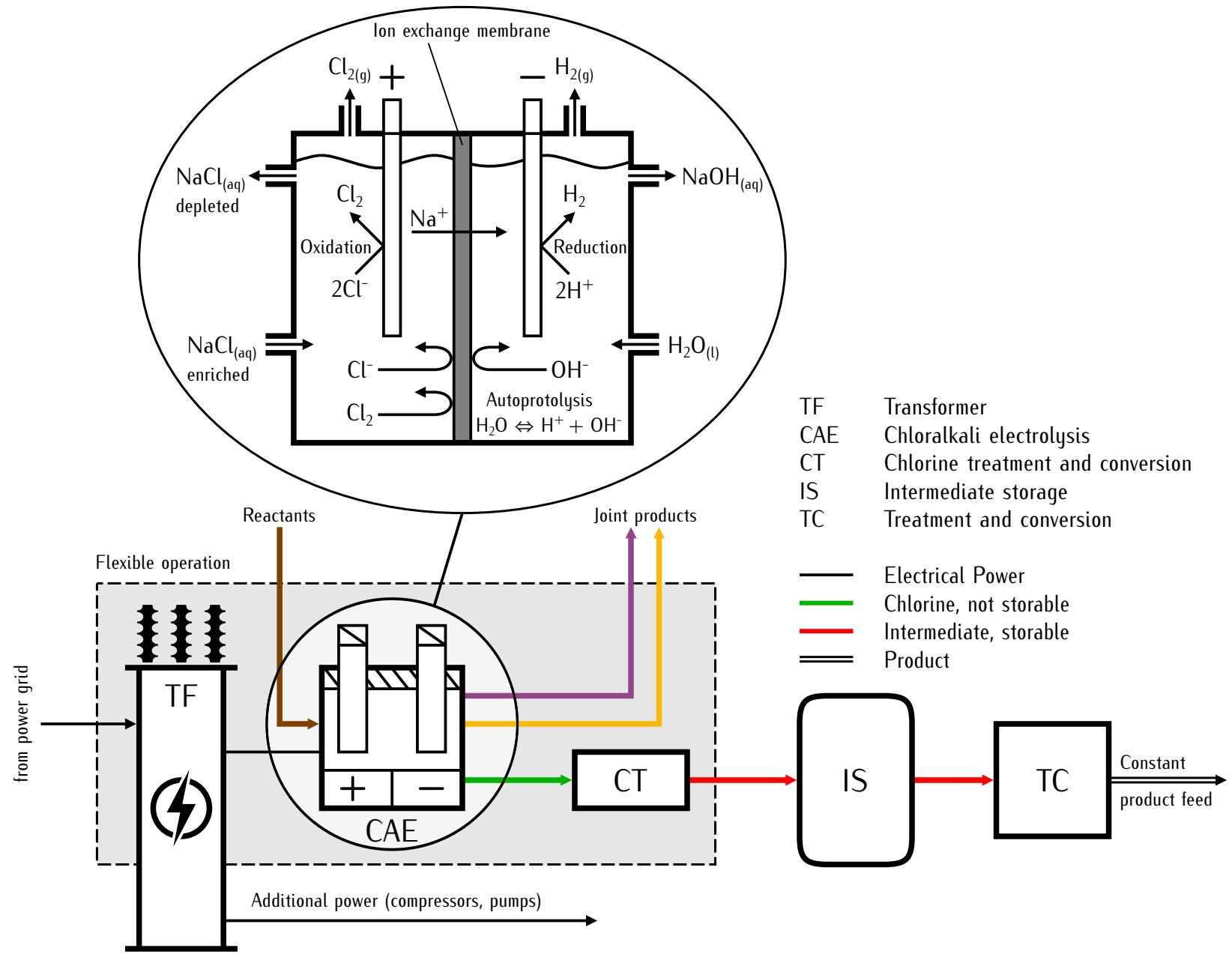

Figure 1: Simplified flow sheet of the CAE and subsequent processes with storage for an intermediate product.

catholyte (right) and allows only sodium ions to pass through. The following reactions occur at the electrodes [17]:

$$
\begin{aligned}
\text { Anode: } & 2 \mathrm{Cl}^{-} \longrightarrow \mathrm{Cl}_{2}+2 \mathrm{e}^{-} \\
\text {Cathode: } & 2 \mathrm{H}_{2} \mathrm{O}+2 \mathrm{e}^{-} \longrightarrow \mathrm{H}_{2}+2 \mathrm{OH}^{-} \\
& \mathrm{Na}^{+}+\mathrm{OH}^{-} \rightleftharpoons \mathrm{NaOH}
\end{aligned}
$$

The current density typically ranges from $1.57 \mathrm{kA} \mathrm{m}^{-2}$ to $7 \mathrm{kA} \mathrm{m}^{-2}$ [17]. It depends on various factors, such as composition of the catholyte, its caustic concentration, the membrane technology, and the age of the membrane [14. As in previous work [13, we assume for the electricity consumption an average value of $2.58 \mathrm{MWh} / \mathrm{t}_{\mathrm{Cl}_{2}}$ based on a literature review. The electricity demand of the electrolysis dominates by far the overall electricity demand of the entire chloralkali process. For instance, the second important electricity consumer is the compression of the chlorine gas. Its power consumption ranges from $5 \mathrm{kWh} / \mathrm{t}_{\mathrm{Cl}_{2}}$ for a 
final pressure of $0.1 \mathrm{MPa}$ to $57 \mathrm{kWh} / \mathrm{t}_{\mathrm{Cl}_{2}}$ for a final pressure of $1.6 \mathrm{MPa}$ [17]. Therefore, the following analysis only considers the demand of the electrolyser.

The sodium hydroxide solution, which leaves the catholyte, has a concentration of up to 32 wt.\% NaOH [17], but may be further concentrated if required. The chlorine gas is cooled, dried and compressed [16]. The gas has an oxygen content of about 1.5 Vol.\% (dry basis) [17. This oxygen is disruptive for some subsequent processes, for example the production of phosgene [18]. To remove these residual gases, a liquefaction step is necessary [17].

The by-product hydrogen is currently primarily used to supply thermal energy by combustion [19] although other applications might be possible in the future, e.g., its use in fuel cells [20]. Chlorine and sodium hydroxide are among the top ten chemicals in terms of production capacity in the world [14]. They are feedstock for about $55 \%$ of the chemicals in the EU 27 and in EFTA countries [19]. Chlorine has more than 40 subsidiary products, including many special chemicals [21]. Currently, Germany is the main producer in the EU 27 and in EFTA countries (45\% of the chlorine production), followed by France (12\%), and Belgium (9\%) [15].

Commercially, sodium hydroxide is typically available as a $50 \mathrm{wt.} \%$ solution [19]. Below $50^{\circ} \mathrm{C}$, the aqueous solution of sodium hydroxide solution can be stored and transported in alkali-resistant steel or plastic vessels [22]. Therefore, production and use of sodium hydroxide are temporally and spatially decoupled and a fluctuating operation of the CAE would have no effect on the subsequent processes consuming sodium hydroxide.

A constant product feed for a chemical facility based on a flexible operation of a CAE may be guaranteed with intermediate storage. The stored substance must fulfil at least three requirements: It should be not highly toxic or highly reactive, present no detectable decomposition over a period of several days, and have low environmental impact in the case of release. Fig. 1 shows a simplified flow sheet valid for every process based on chloralkali process and including intermediate storage. To satisfy the requirements of DR, the CAE as well as the chlorine treatment and conversion must be able to operate flexibly.

\subsection{Challenges for flexibilisation}

Chlorine is an essential raw material for the synthetic organic chemistry and it is often contained in intermediates, although the final products may not contain chlorine anymore [17]. In contrast to sodium hydroxide, storage and transport of chlorine are rather difficult, because it is a strong oxidant [17]. In consequence, chlorine is hazardous to health and the environment even in lowest concentrations in air $(\leq 1 \mathrm{ppm})$ [16, 17]. Accordingly, the safety requirements for its storage are particularly high [17], which strongly constrains DR [9]. If storage is unavoidable, chlorine is stored liquefied at ambient or low temperature [17]. The maximum capacity for individual tanks ranges from $300 \mathrm{t}$ to $400 \mathrm{t}$ [17]. Storing chlorine should be avoided whenever possible and in practice, the storage is limited to a minimum [9]. Usually, chlorine is further processed in reaction or separation steps. Consequently, fluctuations in electrical consumption and thus in the chlorine production are passed on to downstream processes as long as there is no intermediate storage. Hence, the DR potential is highly affected by the capability of flexible operation and storage capacity of these downstream processes, which must be included in the analysis. A holistic assessment of the DR potential 
for the chloralkali process will be consequently only possible if the individual value chains are investigated.

The dynamic operation of the CAE cell has already been discussed in several publications, e.g., Budiarto et al. [23] and Otashu and Baldea [24, 25], who developed dynamic models for this purpose. Otashu and Baldea showed that DR is feasible for the CAE with the restriction that several variables, such as cell temperature, have to be controlled carefully. A further analysis by Brée et al. [26] and Roh et al. [27] investigated an operational mode switching between a standard cathode and an oxygen depolarized cathode for DR. They showed that under the current conditions the standard cathode is more economic. Contrarily, the subsequent processes have hardly been looked at. Hence, we investigate these subsequent processes in the chlorine value chain to identify the relevant processes and to determine their technical potential for DR.

In the following section, we introduce flexibility criteria to assess the potential of each process, and derive four flexibility categories based on these criteria. Section 3 gives an overview of all the chlorine-consuming processes in the industry and determines the relevant processes and their chlorine demand. Section 4 analyses these processes and classifies them to a flexibility category. The results of the analysis for the chloralkali process are presented in section 5. After the conclusions, section 6 presents some ideas for future research.

\section{Methodology and definitions}

This section explains the procedure for evaluating the chlorine subsequent products. Moreover, flexibility is defined and the associate evaluation criteria are established.

\subsection{Significance of a single product}

The most relevant factor for the significance of a specific product is its chlorine consumption. Only if its market share is large enough, the DR potential is significant. To assess this significance, the annual production quantity of the product $m_{i}^{\mathrm{a}}$ is related to the overall production of chlorine $m_{\mathrm{Cl}_{2}}^{\mathrm{a}}$, which yields a proportion of the chlorine demand $x_{\mathrm{Cl}_{2}, i}$ :

$$
x_{\mathrm{Cl}_{2}, i}=\frac{\xi_{\mathrm{Cl}_{2}, i} \cdot m_{i}^{\mathrm{a}}}{m_{\mathrm{Cl}_{2}}^{\mathrm{a}}} \quad \text { with } \quad \xi_{\mathrm{Cl}_{2}, i}=\frac{m_{\mathrm{Cl}_{2}}}{m_{i}}
$$

The chlorine demand $\xi_{\mathrm{Cl}_{2}, i}$ in g per mass of product $i$ is calculated by a mass balance for the chemical reaction. Additionally, this factor is adjusted by the product selectivity and the chlorine demand of side products. The annual mass of the produced product is approximated by a literature review for the overall production capacities of Germany in 2015 whenever possible. If no data were available for the year 2015, data of previous years were used. These older data were extrapolated based on the average increase in production capacity if this information was available. 


\subsection{Flexibility criteria}

In the past, flexibility was assessed by addressing optimisation problems to determine the maximum area of the feasible operating region, see for example [28, 29, 30, 31]. However, these approaches require rigorous process models. Such methods are not suitable in this study due to the wide range of investigated processes and the insufficient information on process details. Instead, categories are developed on the basis of an evaluation of flexibility criteria. This approach will not result in a quantitative description of the feasible region, but rather in a qualitative comparison of processes due to their process flexibility.

According to [28], flexibility of chemical processes includes both the number of options for operating conditions with feasible steady-state operations and the speed of switching between these operating points while ensuring safety, reliability, and quality requirements. Hence, reaction, process, and control engineering have an impact on the flexibility of a process and must be considered. Consequently, the following flexibility criteria are chosen:

\section{Product yield}

A fluctuating chlorine amount may have an effect on the conversion. The selectivity and yield of the product could be affected. Also, the yield of by-products can rise. This results in a lower product quality or in higher expenditure for conversion and treatment steps. Critical factors for this parameter are the stability of the reaction, the number of possible by-products and their selectivity in the reaction. If the conversion is influenced by the chlorine concentration, countermeasures have to be implemented to stabilise the reaction. Examples include adapting the feed of the other reagents to the current chlorine flow, changing the recycle ratio, or adding inert substances.

\section{Temperature conditions}

Chlorine is highly reactive [17]. Moreover, chlorination is mostly an exothermic reaction. Consequently, fluctuations in the chlorine concentration have an effect on the reactor temperature, influencing both the conversion and product quality. In addition, this is safety-relevant as the reactor might undergo thermal runaway. To stabilise the temperature, an additional cooling fluid or an increased heat transfer might be necessary. In the case of decreased chlorine feed, the temperature of the reactor could decline, which would make it necessary to preheat the reactants.

\section{Storing of intermediates or products}

Although storing intermediate products enables decoupling of the single processing stages for flexibilisation, these intermediates must also be easily and safely storable. Other aspects are aggregate state, volatility, and - in the case of mixtures - the chemical composition. The larger the hazardous potential of a substance, the higher the requirements for safety equipment and storage tank materials and thus the costs. Gaseous products have higher storage expenditure than liquids or solids because gas compression requires more energy than pumping a liquid. Additionally, gaseous products require pressure vessels with higher safety standards and possibly cooling. Volatile substances can have similar requirements. Products 
that are dissolved in solvents or mixtures require a larger specific storage volume than pure products, which results in increased investment costs.

All these aspects have an impact on the process and will require an adapted control scheme or additional process equipment. Another significant factor is the cost associated with investment for storage, or reduced profit, in case of poorer product quality.

\subsection{Flexibility categories}

The discussed parameters and their effects on the process flexibility are allocated to flexibility categories A to D. Note that the most restrictive property of a process dictates its categorisation. Tab. 1 summarises these categories regarding their key aspects.

\section{A - Processes with excellent and good potential for flexibilisation}

The reaction is stable and has excellent or good selectivity towards the product and at most two side products. Flexibility has a negligible impact on the product yield or product quality. Minor or no effort is necessary to control the reactor temperature. The control scheme requires only little adjustment to enable flexibilisation. The storage of a product or intermediate is not difficult. This implies low safety or material requirements and the product being liquid or solid and not volatile.

\section{$B$ - Processes with potential for flexibilisation}

The reaction is stable, but the conversion and therefore product selectivity and yield are influenced by the chlorine concentrations. Therefore, a fluctuation in the chlorine feed might lead to a lower product yield and/or a lower product quality. These impediments could be managed by adjusting the control scheme. The reactor temperature depends on the chlorine feed. A stable reactor operation for a fluctuating feed requires some adjustments in the control scheme and/or small modifications of the process design. Storing involves increased safety or material requirements. The product or intermediate is liquid or solid and could be volatile.

\section{$C$ - Processes with restricted potential for flexibilisation}

The reaction is stable, but the conversion is strongly influenced by the chlorine concentration. Considerable adjustments of the control scheme and/or modifications of the process design are necessary to avoid a lower product yield and/or a lower product quality. The reactor temperature depends on the chlorine feed and a flexibilisation is only possible with considerable adjustments of the control scheme and/or modifications of the process design. High safety standards are required for storing, for example gaseous or highly volatile products.

\section{$D$ - Processes with excluded potential for flexibilisation}

Changes in the chlorine concentration have an impact on the product yield and/or quality because the reaction is highly unstable and the quantity of side products increases significantly. The reactor temperature depends on the chlorine feed. It requires extraordinary adjustments of the control scheme or the process design to ensure a constant temperature. Flexible 
Table 1: Summary of the flexibility categories and their requirements.

\begin{tabular}{cccc}
\hline Category & Impact on yield & Temperature stability & Storage requirements \\
\hline A & Negligible & Negligible & Low or normal \\
B & Low & Slightly dependent on the chlorine feed & Increased \\
C & High & Strongly dependent on the chlorine feed & High \\
D & Highly unstable & Increased hazard potential & Impossible to store \\
\hline
\end{tabular}

operation increases the hazard potential and may result in breaches of safety standards. The obstacle of the intermediate stages is only manageable with considerable adjustments of the control scheme. The product or intermediate is highly hazardous, so that storage is hardly possible or impossible.

\subsection{Quantification of the demand response potential of the chlorine value chain}

Basis for the calculation of the DR potential is the annual electricity demand $W_{\mathrm{el}, i}^{\mathrm{a}}$ for each value chain $i$, which is computed by the annual demand of chlorine $m_{\mathrm{Cl}_{2}, i}^{\mathrm{a}}$ for the product $i$ and the specific electrical energy consumption per mass of chlorine given in Sec. 1.1. As explained in Sec. 1, the overall electricity consumption of the chloralkali process is dominated by the electrolysis. This also applies to the electricity demand of the subsequent processes. Significant consumers are here pumps and compressors, with a low consumption compared to the CAE. Moreover, necessary information is lacking to determine this additional demand. Therefore, only the demand of the electrolysis is taken into account to determine the potential of load reduction. The annual demand of chlorine for the product $i$ results from its annual produced mass $m_{i}^{\mathrm{a}}$ and the associated chlorine demand iin g per mass of product $\xi_{\mathrm{Cl}_{2}, i}$ :

$$
W_{\mathrm{el}, i}^{\mathrm{a}}=m_{\mathrm{Cl}_{2}, i}^{\mathrm{a}} \cdot e_{\mathrm{el}, \mathrm{Cl}_{2}} \text { with } m_{\mathrm{Cl}_{2}, i}^{\mathrm{a}}=m_{i}^{\mathrm{a}} \cdot \xi_{\mathrm{Cl}_{2}, i}
$$

Subsequently, the potential of load reduction $P_{\mathrm{DR}, i}$ is calculated by the the annual electricity demand, the hours per year at full load $t_{\mathrm{f}}$, and the average DR of load reduction of a membrane cell $s_{\mathrm{DR}}$.

$$
P_{\mathrm{DR}, i}=\frac{W_{\mathrm{el}, i}^{\mathrm{a}}}{t_{\mathrm{fl}}} \cdot s_{\mathrm{DR}}
$$

The average DR for load reduction of the membrane CAE was determined to be $48 \%$ in a previous study [13] and the hours per year at full load consider $24 \mathrm{~h}$ operation for the full year.

Additionally, the specific electrical energy per mass of product $\mu_{\mathrm{el}, i}$ is calculated. This efficiency indicator describes how much electrical energy can be stored in $1 \mathrm{~kg}$ of the product.

$$
\mu_{\mathrm{el}, i}=\xi_{\mathrm{Cl}_{2}, i} \cdot e_{\mathrm{el}, \mathrm{Cl}_{2}}
$$

\section{Analysis of processes}

Although chlorine is part of the production process for more than 40 chemicals, not all of them are relevant for the flexibility analysis in this study. The chlorine-based products 
Table 2: Overview of the chlorine-based products in Germany. The stated annual production refers to the reference year.

\begin{tabular}{|c|c|c|c|c|}
\hline Product $i$ & $\begin{array}{l}\text { Chlorine demand } \mathrm{g} \\
\text { per mass of product } \\
\qquad \xi_{\mathrm{Cl}_{2}, i}\end{array}$ & $\begin{array}{c}\text { Annual } \\
\text { production } \\
m_{i}^{\mathrm{a}} \text { in } \mathrm{kt} \mathrm{a}^{-1} \\
\end{array}$ & $\begin{array}{c}\text { Reference } \\
\text { year }\end{array}$ & Reference \\
\hline 1,2-Dichloroethane (DCE) & 0.36 & 2238 & 2015 & 32 \\
\hline $\begin{array}{l}\text { 4,4'-Diphenylmethane diiso- } \\
\text { cyanate (MDI) }\end{array}$ & 0.57 & 617 & 2015 & [33, 32] \\
\hline Propylene oxide & $1.33^{\mathrm{a}}$ & $381^{\mathrm{b}}$ & 2015 & 34 \\
\hline Toluene diisocyanate (TDI) & 0.81 & 343 & 2015 & 33,32 \\
\hline Polycarbonate & $0.28^{c}$ & 284 & 2015 & 34 \\
\hline Epichlorohydrin (ECH) & $1.64^{\mathrm{d}}$ & 213 & 2006 & 33,35 \\
\hline Chloroacetic acid (CA) & 0.75 & 105 & 2004 & 33 \\
\hline Tetrachloroethylene & 0.43 & 100 & 2000 & 33 \\
\hline Monochlorobenzene & 0.63 & 77 & 1999 & 33,36 \\
\hline Dichloromethane & 0.83 & 77 & 2015 & 34 \\
\hline Chloroprene & $0.83^{\mathrm{e}}$ & 60 & 1983 & 37 \\
\hline Phosphorus trichloride & 0.77 & 55 & 2002 & 38 \\
\hline Semiconductor silicon & $0.5^{\mathrm{f}}$ & 51 & 2014 & 39 \\
\hline Trichloromethane & 1.19 & 46 & 2015 & 34 \\
\hline Trichloroethylene & 0.27 & 30 & 2000 & 33 \\
\hline 1,4-Dichlorobenzene & 0.96 & 27 & 1999 & 33,36 \\
\hline Tetrachloromethane & 1.38 & 7 & 2015 & 34 \\
\hline
\end{tabular}

${ }^{a}$ Adjusted by the average of yield for the propylene chlorohydrin isomers $92 \%$ based on propene [40, main by-product 1,2-dichloropropan 33.

b Hydro-chlorination route with a share $43 \%$ of the global overall production capacity 41.

c Assumed weight-average of the molar masses $26500 \mathrm{~g} \mathrm{~mol}^{-1}$ according to 42 .

d Allyl chloride routes, adjusted by the chlorine conversion of $86 \%$ of the allyl chloride step 43 .

e Butadiene route, adjusted by average of selectivity for chloroprene $97 \%$, by-product 1,3-dichloro-2-butene 33 .

$\mathrm{f}$ The loss of hydrogen chloride in a production network of ultrapure silicon, silicones, and highly dispersed silicic acid is $4 \%$ to $6 \%$ according to the corporate communications of Wacker Chemie AG 2018.

with the highest chlorine demand were identified in a literature review. However, published statistics on this matter are incomplete. For example, the work of Bommaraju et al. [16] is short in detail and only carried out for the U.S. industry, whereas the Euro Chlor statistics [15] only state the cumulative amount of all chlorine subsidiary products. In 2015, the overall chlorine production $m_{\mathrm{Cl}_{2}}^{\mathrm{a}}$ in Germany was $3867 \mathrm{kt}_{\mathrm{Cl}_{2}}$ [32]. Tab. 2 lists the analysable chlorinebased products, their annual production capacity in Germany, and their chlorine demand in g per mass of product.

A calculation of the chlorine demand was not possible for the following products:

- Aluminium chloride, sulphur chlorides, nitrogen trichloride, chlorine oxides, and chlorinated paraffins. No adequate data for the production volume could be found in the literature for these components. 
- Potassium and sodium chlorate were not considered because their production involves special electrolysis cells, which are often located close to the place of consumption [44].

- 1,2-Dichloroethene and 1,1,1-trichloroethane are not taken into account due to the ban under the Montreal Protocol [45].

- Titanium dioxide was not considered because the mass balance for this product could not be closed as its chlorine demand depends strongly on the composition of the raw material and its purity.

- Chloromethanes do not include methyl chloride, which is prepared predominantly from methanol using hydrogen chloride [33]. The hydrogen chloride is typically a by-product of other processes, e.g. PVC production, and does not arise from the chloralkali process [46]. Higher chlorinated methanes are produced most commonly by direct chlorination of methyl chloride [47]. Hence, their Chlorine demand in g per product mass is based on the educt methyl chloride.

- Chlorinated benzenes are only considered in the cases of monochlorobenzene and 1,4-dichlorobenzene. Data for other chlorinated benzenes is not available.

Fig. 2 represents the proportion of the chlorine demand per product $i$. Due to the uncertainty associated with production capacities, the values for normalized chlorine demand per product are not necessarily exact but they give an overview regarding more important and less important production paths and their significance for the overall flexibility potential of the chloralkali process. In total, $28 \%$ of the chlorine could not be accounted for, for the reasons given above. Additionally, these $28 \%$ include the uncertainties in the calculations for the other products, due to, for example, imprecise production quantities or by-products.

In the following, only processes with $x_{\mathrm{Cl}_{2}, \mathrm{x}} \geq 2 \%$ are considered. Processes below this limit are neglected due to their small potential for DR. Hence, the following products are further considered and marked in Fig. 2 by bold letters:

1. 1,2-Dichloroethane (DCE)

2. Phosgene and subsequent processes

- The diisocyanates 4,4'-diphenylmethane diisocyanate (MDI) and toluene diisocyanate (TDI)

- Polycarbonate

3. Propylene oxide: produced by the hydrochlorination route

4. Epichlorohydrin (ECH), produced via the allyl chloride route

5. Chloromethanes: with di-, tri- and tetrachloromethane, produced by chlorination of methyl chloride

6. Chlorinated benzenes

7. Chloroacetic acid (CA) 


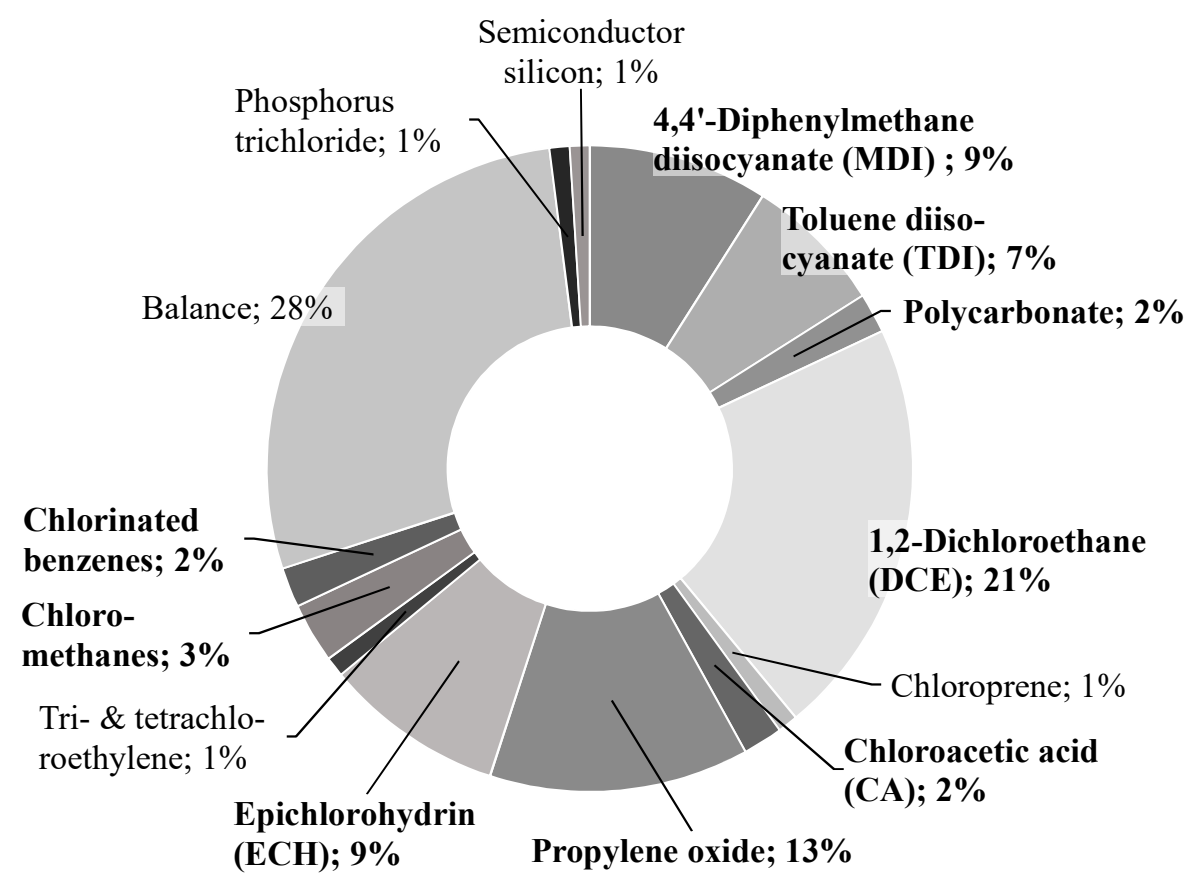

Figure 2: Proportion of the chlorine demand $\left(x_{\mathrm{Cl}_{2}, i}\right)$ for the chlorine-based products. The group 'chloromethanes' contains Di-,tri-, and tetrachloromethane while 'Chlorinated benzenes' comprises 1,4-dichlorobenzene and monochlorobenzene. Boldly printed products with $x_{\mathrm{Cl}_{2}, i} \geq 2 \%$ are considered in the further analysis..

These processes consume $68 \%$ of the total electricity demand of the chloralkali electrolysis in Germany. Due to this high percentage, focusing on these processes allows for an assessment of the actual DR potentials of the chloralkali process in Germany. Moreover, as Germany is the main chlorine producer within the EU, these results are assumed to be representative for other countries with a well-developed electrochemical industry.

\section{Analysis of flexibility}

In the following, the process of the selected subsequent products are described and analysed regarding their flexibility potentials towards a fluctuating chlorine feed.

\subsection{1,2-Dichloroethane}

1,2-Dichloroethane (DCE) is used primarily for PVC production [45]. Previous investigations of this process by Ausfelder et al. [9] have revealed some flexibility potential. The industrial production is carried out based on two reactions of ethene [45]:

$$
\begin{aligned}
& \text { Direct chlorination: } \mathrm{C}_{2} \mathrm{H}_{2}+\mathrm{Cl}_{2} \longrightarrow \mathrm{C}_{2} \mathrm{H}_{2} \mathrm{Cl}_{2} \\
& \text { Oxychlorination: } 2 \mathrm{C}_{2} \mathrm{H}_{2}+4 \mathrm{HCl}+\mathrm{O}_{2} \longrightarrow 2 \mathrm{C}_{2} \mathrm{H}_{2} \mathrm{Cl}_{2}+2 \mathrm{H}_{2} \mathrm{O}
\end{aligned}
$$

In practice, both reactions are used at different locations of typically highly integrated plants, as the hydrogen chloride is a by-product of the subsequent vinyl chloride production [33. 


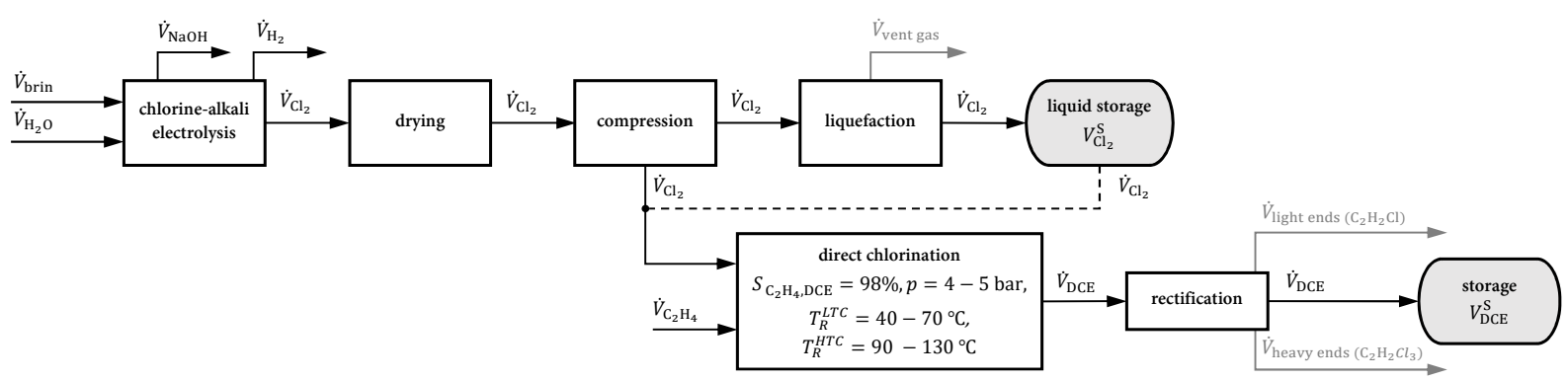

Figure 3: Simplified flow chart of the synthesis of 1,2-dichloroethane by direct chlorination, based on 33, 45.

\section{Process description}

In this process, chlorine is dried, compressed, and possibly liquefied, see Fig. 3. A small storage tank might be available on-site to buffer small changes in production. The compressed chlorine is fed to a reactor to chlorinate ethene to DCE [45]. DCE production involves only one reactor and one separation step, which can also be directly performed in one apparatus if the reactor serves as reboiler for the column. All following units can still be operated at steady-state as there is a continuous DCE feed from the storage tank. Hence, the oxychlorination is not relevant for this analysis.

\section{Storage}

Pure 1,2-dichloroethane is sufficiently stable up to $340^{\circ} \mathrm{C}$ and is a liquid under ambient conditions [45]. It is categorised as a carcinogenic [48] and is flammable [45]. 1,2-Dichloroethane should be dry for storage, because its decomposition through hydrolysis may lead to excessive corrosion [45].

\section{Flexibility categorisation}

This one-stage process is characterised by a high product selectivity and a stable reaction. An increasing amount of the side product trichloroethane due to flexibilisation could be avoided by adjusting the ethene feed to the chlorine feed, which is already done in practice. Hence, the impact of the flexibilisation on the product yield is expected to be negligible. To control the reactor temperature in the case of load reduction, additional external heating might be necessary if the reactor serves as reboiler for the separation step. However, the enthalpy of reaction is seven times larger than the heat of vaporisation of DCE. This is thus only treated as a mildly restrictive aspect. The DCE process satisfies the criteria for flexibility: the product yield and the reactor temperature could be stabilised by a few adjustments, there are no intermediate steps, and DCE is storable. Consequently, 1,2-dichloroethane is classified in flexibility category A.

\subsection{Phosgene production and subsequent processes}

Phosgene is an intermediate for the synthesis of many commercial materials, of which polyurethane and polycarbonate account for the largest demand [18]. As diisocyanate and 
polycarbonate production use the intermediate phosgene, their analyses are both included in this section.

The reaction of carbon monoxide and chlorine to phosgene is highly exothermic and very fast [49]:

$$
\mathrm{CO}+\mathrm{Cl}_{2} \longrightarrow \mathrm{COCl}_{2} \quad \Delta H^{\ominus}=-107.6 \mathrm{~kJ} \mathrm{~mol}^{-1}
$$

\section{Process description}

The synthesis takes place in a multitubular reactor and is catalyzed by activated charcoal with a temperature around $150^{\circ} \mathrm{C}$ up to a maximum of $400{ }^{\circ} \mathrm{C}$ close to the reactor inlet [18]. The educts are mixed stoichiometrically, with a slight excess of carbon monoxide to ensure complete reaction of chlorine [50]. For safety reasons, chlorine should be free of oxygen [18]. The conversion is typically about $99 \%$ [18. The reaction heat should be removed rapidly otherwise phosgene tends to dissociate again [18. A purification step for phosgene is usually unnecessary due to the high selectivity of the catalyst [49].

\section{Storage}

Phosgene is highly toxic and corrosive [50]. Therefore, storing it should be avoided whenever possible [49].

\section{Flexibility categorisation}

The process is characterised by a high conversion and a stable reaction with marginal by-products. Therefore, the product yield is stable in the case of flexibilisation. The reactor temperature is controlled by adjusting the carbon monoxide or the inert gas flow to the chlorine flow. This speaks in favour of flexibilisation. However, storing phosgene is virtually impossible because of safety hazards. Therefore, a classification to the flexibility category D is necessary. Consequently, the dynamic chlorine fluctuations would not be compensated by the phosgene synthesis but would propagate further to the next processing steps. As mentioned above, phosgene is an intermediate for a large number of products. The main subsequent products - the diisocyanates MDI and TDI, and the polycarbonate - are analysed regarding a flexible phosgene feed.

\subsubsection{Phosgene route A - Diisocyanate}

Diisocyanate is an intermediate of polyurethane production and is produced by phosgenation of free amines:

$$
\mathrm{COCl}_{2}+\mathrm{R}-\mathrm{NH}_{2} \longrightarrow \mathrm{R}-\mathrm{N}=\mathrm{C}=\mathrm{O}+2 \mathrm{HCl}
$$

The reaction has two stages. Firstly, the intermediate carbamic acid chloride (CAC) is formed, and secondly, hydrogen chloride $(\mathrm{HCl})$ is eliminated [51].

\section{Process description}

Fig. 4 describes the process flow and conditions. The solution of amine in organic solvents is added to the reactor with excess phosgene [52] at temperatures ranging from $20^{\circ} \mathrm{C}$ to $50{ }^{\circ} \mathrm{C}$ [33]. The first reaction stage to $\mathrm{CAC}$ is exothermic and fast [53]. Subsequently, the 


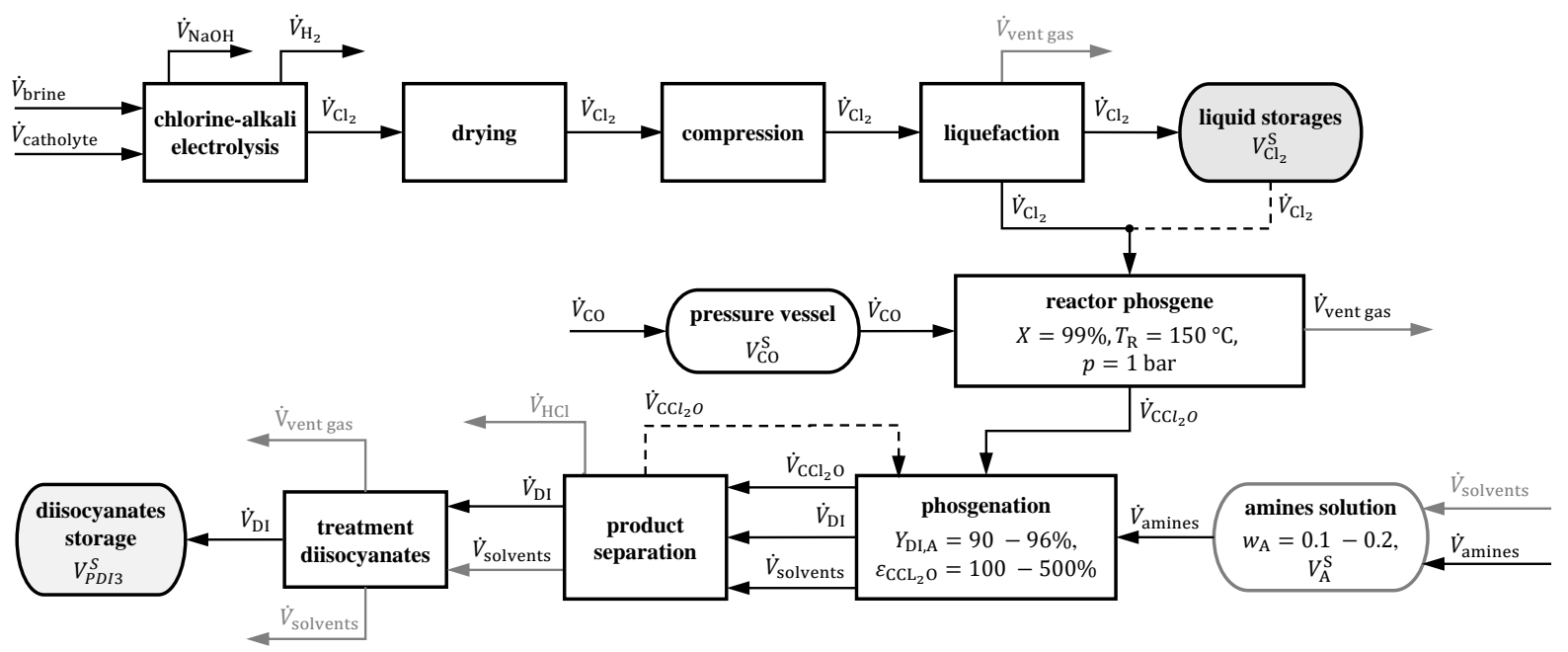

Figure 4: Simplified flow chart of the diisocyanate process, based on [18, 33, 52, 53].

reaction mixture is phosgenated and $\mathrm{HCl}$ is removed [54]. There is no spatial separation of both reactions [52] in continuous processes and the heat of reaction of the first stage is used for the endothermic second stage [53. To avoid the side reaction of CAC with already formed diisocyanate to urea compounds, an excess of phosgene is required [53]. The required excess ranges from $100 \%$ to $500 \%$ [52] or from $50 \%$ to $200 \%$ [53].

\section{Storage}

In general, diisocyanates are toxic and should be stored under high safety precautions [55]. The storage should be dry, to avoid a reaction with water [52. In addition, TDI and many aliphatic isocyanates have high vapor pressures [55] even though the diisocyanates are mostly liquid at ambient temperature. At an elevated temperature, product cyclodimerization and dimerization [52] as well as discoloration may appear and the viscosity could increase. To prevent this, sufficient cooling is necessary [55].

\section{Flexibility categorisation}

Regarding the criterion product yield, the dependency of the second reaction towards the phosgene concentration is crucial for flexibility. As dearth of phosgene leads to the formation of urea compounds, the process cannot easily be made flexible without decreasing the diisocyanate yield. However, as the phosgene reactor typically operates at a large excess, this enables flexibility by exploiting the limits of the necessary phosgene excess without an impact on the product yield.

Effects on the reactor temperature are only expected for a significantly reduced phosgene feed. In this case, a reduced conversion of the first exothermic reaction would also reduce the generated heat. Due to the fact that a reduction of the phosgene flow is only possible within narrow limits, this effect is negligible.

The high safety requirements for storage entail high opportunity costs and impede flexibilisation in the case of load relinquishment. Due to the fact that an economic product 


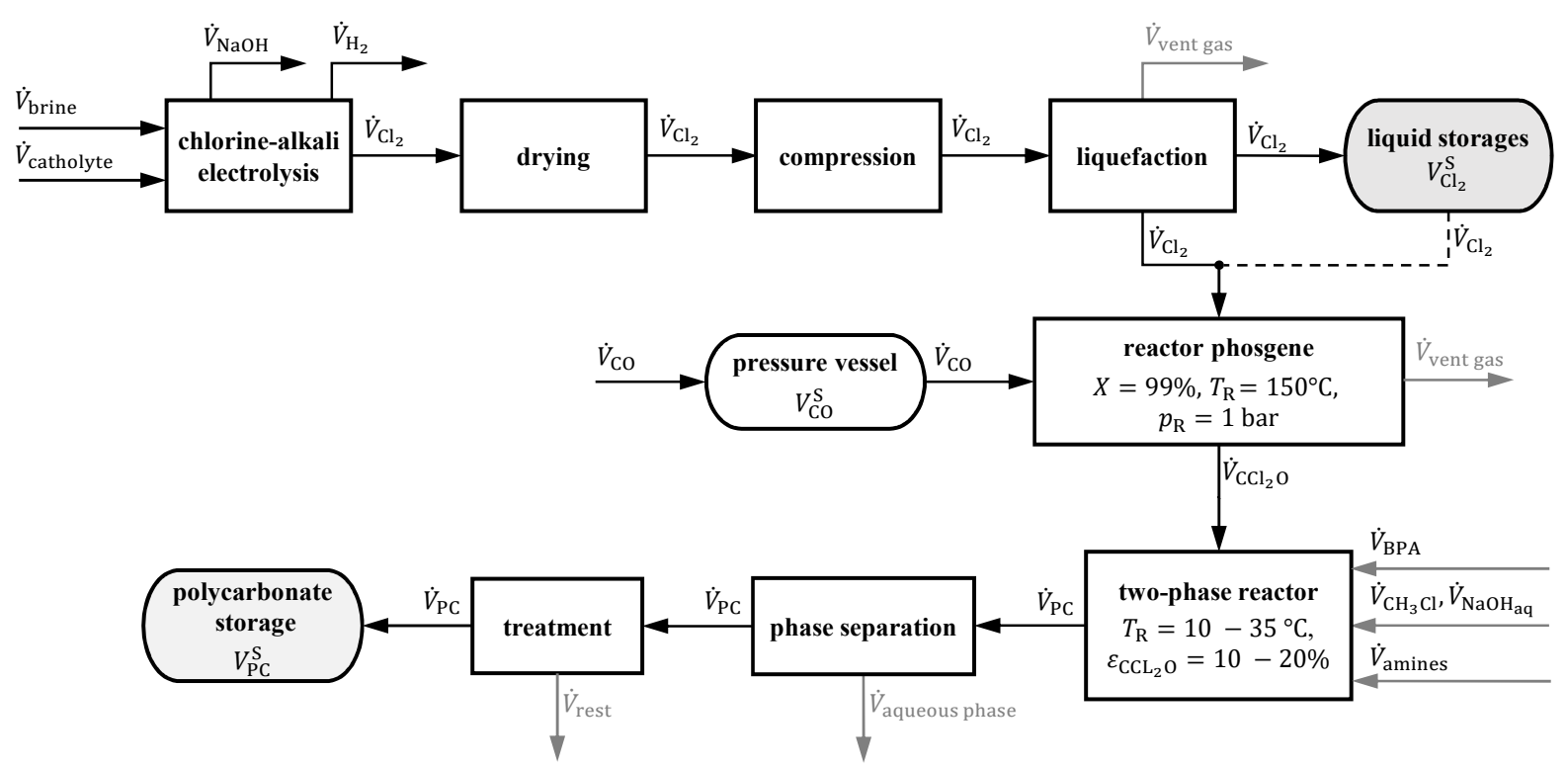

Figure 5: Simplified flow chart of the polycarbonate process, based on [18, 156, 42,

imposes certain limits on the phosgene feed, the diisocyanate process is assigned to the flexibility category $\mathrm{C}$.

\subsubsection{Phosgene route $B$ - Polycarbonate}

Polycarbonates are produced by the reaction of bisphenols with carbonic acid derivatives, bisphenol A being the most important one [42]. There are essentially two routes: interfacial polycondensation, and melt transesterification. The latter has less economic importance [56] and is phosgene-free. For these reasons, it is excluded in the following.

\section{Process description}

Fig.5 shows the flow chart of the polycondensation process. A two-phase mixture of bisphenol, dilute brine, and an organic solvent (typically dichloromethane) is fed into the reactor [42]. The reaction of phosgene and bisphenol occurs at the interface. Phosgene is dissolved in the organic phase while bisphenol is dissolved in the aqueous phase as sodium bisphenolate [56]. To compensate for the phosgene loss due to hydrolysis, an excess of $10 \mathrm{~mol} . \%$ to $20 \mathrm{~mol} . \%$ phosgene is used [42. The synthesis occurs in a multi-stage reaction. It starts with the formation of mono- and di-chloroformate [56]. These chloroformates react with the bisphenolate to polycarbonate, catalyzed by tertiary aliphatic amines [42]. A ratio of phenolate to chloroformate end groups $\geq 1$ is advantageous for the formation of high-molecular polycarbonate. Otherwise, the saponification reactions stagnate and the polymerisation remains at a low level, because the phenolate end groups cannot react with themselves [56]. 


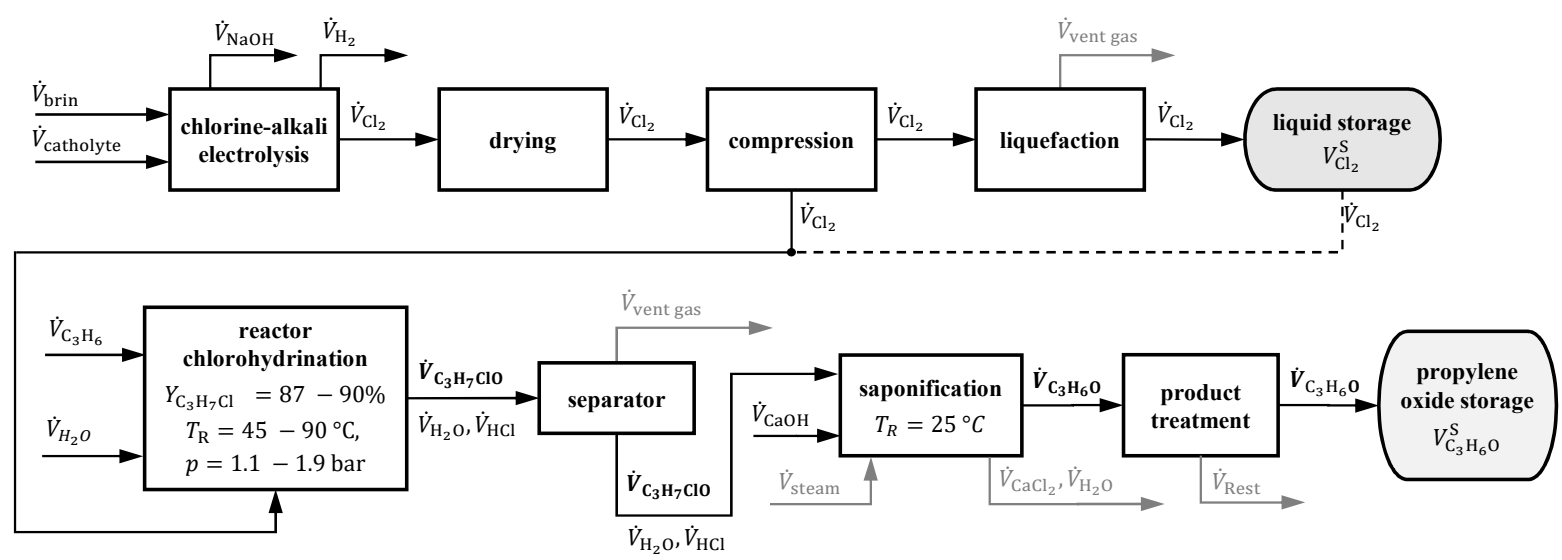

Figure 6: Simplified flow chart of the propylene oxide process, based on [33, 57, 40, 58, 59].

\section{Flexibility categorisation}

As the reaction requires a specific ratio of the end groups chlorformiate to phenolate, the flexibilisation is severely hindered. Fluctuations in the phosgene feed would affect the chain length of the polycarbonate and have a great impact on the product yield. Hence, the polycarbonate process cannot operate flexibly and is assigned to flexibility category D.

\subsection{Propylene oxide}

Propylene oxide is produced by a variety of processes. The chlorohydrin process is the most important one [41]. It consists of two reactions [33]:

1. Chlorohydrination: Propene reacts in aqueous solution with chlorine to the isomers 1-chloro-2-propanol (90\%) and 2-chloro-1-propanol (10\%).

$$
\mathrm{C}_{3} \mathrm{H}_{6}+\mathrm{H}_{2} \mathrm{O}+\mathrm{Cl}_{2} \longrightarrow \mathrm{C}_{3} \mathrm{H}_{6} \mathrm{ClOH}+\mathrm{HCl}
$$

The chlorohydrination step has several by-products. The main one is 1,2-dichloropropane with a yield of $3 \%$ to $10 \%$ based on propene [40].

2. Dehydrochlorination/saponification: Chlorohydrin reacts with caustic soda or calcium hydroxide to propylene oxide

$$
2 \mathrm{C}_{3} \mathrm{H}_{6} \mathrm{ClOH}+\mathrm{Ca}(\mathrm{OH})_{2} \longrightarrow 2 \mathrm{C}_{3} \mathrm{H}_{6} \mathrm{O}+\mathrm{CaCl}_{2}+2 \mathrm{H}_{2} \mathrm{O}
$$

\section{Process description}

The chlorohydrin process and its specifications are shown in Fig. 6. Firstly, chlorine is dissolved in water, forming a mixture of hypochlorous acid and $\mathrm{HCl}$ [33]. Subsequently, the propene is fed into the middle of the reactor tower [57]. At this point, no free gaseous chlorine should remain, as direct contact with propene may lead to an explosive mixture [58]. Furthermore, a constant chlorine to water ratio and water excess are important [33]. The 
water excess reduces side reactions and is used for direct cooling [40]. There is no information regarding the influence of the isomers on the product yield.

The reaction mixture of the first step passes a separator to remove the remaining gases and is fed into the saponification reactor [40]. The dehydrochlorination to propylene oxide after mixing with lime or $\mathrm{NaOH}$ is rapid [60]. Propylene oxide is quickly steam-stripped from the brine solution to avoid the hydrolyzation to 1,2-propanediol [40]. This operation is carefully controlled to prevent stripping unreacted chlorohydrin [60]. Based on propene, the selectivity of the overall process for propylene oxide varies between $87 \%$ and $90 \%$ [33].

\section{Storage}

Propylene oxide is liquid at ambient temperature. It is reactive and highly flammable [60]. Therefore, high safety standards are required, including an inert atmosphere [60]. The maximum storage temperature is $35^{\circ} \mathrm{C}$ according to the low normal boiling point of $34.23{ }^{\circ} \mathrm{C}$ [40]. The storage tanks should be made of steel or stainless steel [60].

\section{Flexibility categorisation}

A decoupling of the chlorohydrination and dehydrochlorination steps is impossible. Firstly, the resulting mixture still contains hypochlorous acid, thus undesired reactions to by-products are possible. Secondly, the product is highly diluted in water, which results in high costs for storage related to the product volume.

A rising chlorine feed would impair the product yield of the chlorohydrination step. The process is characterised by several side reactions, which are hindered by a constant water ratio in the educt mixture. Therefore, a rising chlorine amount without a declining product yield is only possible if the chlorine to water ratio is kept constant. One possibility for flexibilisation is to adjust the quantity of the other educts related to the chlorine feed. The limit is set by the fact that chlorine should be dissolved completely in water to avoid safety hazards. A reduced chlorine flow rate has less effect on the product yield but it will lower the conversion of propene. This reduces the cost effectiveness, because it increases the mass flow rate of the recycle stream. The loss of propene, which is the most expensive educt, is expected to be very small as the vent gas is recycled [40].

Flexibilisation in the dehydrochlorination step could imply a negative impact on the product yield. The conversion of chlorohydrin in the case of an increased concentration could be incomplete because of a too low base concentration. This is manageable by adapting the base feed to the changes in the chlorohydrin concentration. It also avoids a waste of base in the case of a reduced concentration. Regarding an excessive dilution of the educts, no effect on the reactor temperature in both steps is expected. A storage for propylene oxide relating to flexibilisation is possible, but requires high safety standards and implies increased requirements and expenses.

In summary, the flexibilisation of the propylene oxide process is possible but restricted, mainly by the impacts on the product yield. Moreover, considerable adjustments to the process control are necessary to avoid a lower product yield. Additionally, the increase of chlorine feed is limited by safety hazards. Hence, the propylene oxide process is assigned to the flexibility category $\mathrm{C}$. 


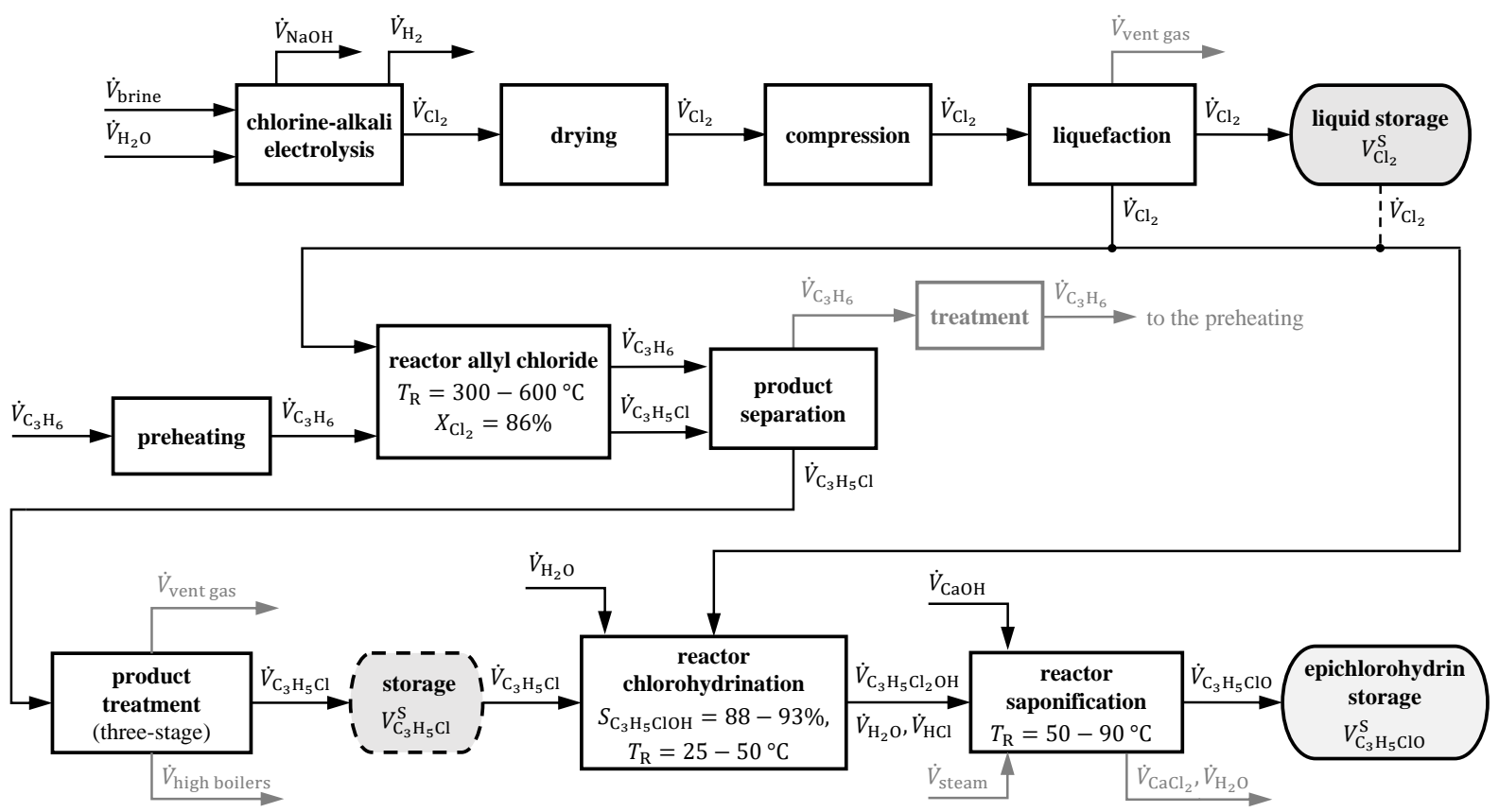

Figure 7: Simplified flow chart of the ECH process, based on [33, 43, 57, 62, $S_{\mathrm{x}}$ based on allyl chloride.

\subsection{Epichlorohydrin}

Epichlorohydrin $(\mathrm{ECH})$ is produced by two industrial processes: the glycerin route and the propene route via allyl chloride [61]. Here, the dominant commercial propene route is analysed [61]. The process has conventionally three steps [33]:

1. Direct chlorination of propene to allyl chloride (3-chloropropene):

$$
\mathrm{C}_{3} \mathrm{H}_{6}+\mathrm{Cl}_{2} \longrightarrow \mathrm{C}_{3} \mathrm{H}_{5} \mathrm{Cl}+\mathrm{HCl} \quad \Delta H^{\ominus}=-113 \mathrm{~kJ} \mathrm{~mol}^{-1}
$$

The direct chlorination of propene to of allyl chloride is fast and exothermic [43].

2. Reaction of allyl chloride with hypochlorous acid to the isomers 1,3-dichloro-2-propanol and 2,3-dichloro-1-propanol, ratio: 70:30 [57]:

$$
\mathrm{C}_{3} \mathrm{H}_{5} \mathrm{Cl}+\mathrm{Cl}_{2}+\mathrm{H}_{2} \mathrm{O} \longrightarrow \mathrm{C}_{3} \mathrm{H}_{5} \mathrm{Cl}_{2} \mathrm{OH}+\mathrm{HCl}
$$

3. Saponification with caustic soda [57] or calcium hydroxide [33] to ECH:

$$
2 \mathrm{C}_{3} \mathrm{H}_{5} \mathrm{Cl}_{2} \mathrm{OH}+\mathrm{Ca}(\mathrm{OH})_{2} \longrightarrow 2 \mathrm{C}_{3} \mathrm{H}_{5} \mathrm{ClO}+2 \mathrm{H}_{2} \mathrm{O}+\mathrm{CaCl}_{2}
$$

\section{Process description}

Figure 7 shows the flow chart and the relevant process parameters. The process is characterised by a high chlorine demand and large quantities of waste water [43. To avoid by-products such as 1,2-dichloropropane in the allyl chloride step, a constant temperature 
$\left(300{ }^{\circ} \mathrm{C}\right.$ to $\left.600{ }^{\circ} \mathrm{C}\right)$ and an excess of propene are important 63. The highest selectivity of $85 \%$ with respect to chlorine can be achieved at $500^{\circ} \mathrm{C}$ to $510^{\circ} \mathrm{C}\left[33\right.$. Above $600{ }^{\circ} \mathrm{C}$, benzene is formed and the yield decreases; below $300^{\circ} \mathrm{C}$, the share of 1,2 -dichloropropane increases [43]. The reactor temperature is controlled by preheating of propene and by the chlorine to propene ratio. In practice, there is a specific chlorine to propene ratio for every preheating temperature [63]. Additionally, many reactors have cooling systems [43]. The unreacted propene is separated from the waste gas and recycled [43].

The reaction of allyl chloride with hypochlorous acid of the second step is comparable to the chlorohydrination step of the propylene oxide process. Allyl chloride is dissolved and suspended in water, in a volume ratio range from 10:1 to 50:1 [57]. Mainly, the chlorine is dissolved in the same reactor as allyl chloride but in a different part [58]. Another option is to prepare the solution in a separate packed column 62. Similarly to the propylene oxide process, a constant high water ratio with a low concentration of chloride $\left(4.4 \mathrm{~g} \mathrm{l}^{-1}\right.$ to $30 \mathrm{gl}^{-1}$ [62]) and chlorohydrin is decisive for the product yield, because this minimizes the formation of by-products [57]. There is no information available regarding reaction and process requirements of the subsequent saponification to epichlorohydrin. Hence, it is assumed that the same requirements as for the saponification of propylene oxide apply.

\section{Storage}

Allyl chloride has a normal boiling point of $44.4^{\circ} \mathrm{C}$ and can be stored for months in ferrous tanks under dry conditions and at ambient temperatures without significant changes in quality [43]. However, safety equipment is needed due to its toxicity, high reactivity, and high flammability [63].

Hypochlorous acid is unstable and should be used immediately after production [44]. Only solutions containing less than $1 \%$ hypochlorous acid can be stored over a longer period [44].

$\mathrm{ECH}$ has a normal boiling point of $116.56^{\circ} \mathrm{C}$ and is moderately toxic [64 but also flammable and highly reactive if it gets in contact with strong acids, bases, or oxidizing agents [65]. It is not sensitive to moisture or air [66] and can be stored if the appropriate safety requirements are fulfilled [65].

\section{Flexibility categorisation}

Due to the fact that allyl chloride is storable with corresponding safety requirements, the multistep process of ECH is separable for flexibilisation in the allyl chloride step and the chlorohydrination step with subsequent saponification. Therefore, these steps are analysed separately.

Flexibilisation of the allyl chloride step will affect the product yield and the reactor temperature for two reasons: Firstly, an optimal product yield needs a constant excess of propene and a specific temperature range. Secondly, the chlorine feed is used as one control variable for the reactor temperature. In this light, a fluctuating chlorine feed is only realisable if the propene feed and the preheating temperature are properly regulated. Therefore flexibilisation requires few adjustments, but these are often already implemented in the control process. Additionally, the prescribed temperature range restricts the fluctuation of the chlorine feed and defines the maximum load reduction for the CAE. Statements about 
the impact of flexibilisation on the product treatment are not possible due to the limited available information. Storing allyl chloride directly after the reactor is an option to avoid impacts on the separation columns. In summary, the flexibilisation of the allyl chloride step is possible, but to avoid impacts on the product yield and the reactor temperature, manageable adjustments in the control scheme are necessary. Therefore, the step is grouped into the flexibility category B.

Due to the similar requirements, the flexibility of the chlorohydrination step has comparable limitations for flexibilisation to the corresponding propylene oxide steps. The fluctuation of the chlorine feed would negatively affect the product yield, because the allyl chloride and especially the water quantity have to be controlled relative to the chlorine quantity to minimize the formation of by-products. To avoid this, the water and the allyl chloride feed have to be adjusted to the chlorine feed. At the required concentrations, an intermediate storage for hypochlorous acid is excluded. The requirements for the subsequent saponification are the same as in the propylene oxide step. ECH is easily storable with regard to safety requirements. Finally, the chlorohydrination step requires considerable adjustments to avoid impacts on the product yield, related to the propylene oxide process and is assigned to category C.

As mentioned, the ECH process can be separated into the allyl chloride step and the chlorohydrination step by storing allyl chloride. This will be taken into account in the subsequent analysis. Therefore, the calculated chlorine demand in $\mathrm{g}$ per allyl chloride is $\xi_{\text {allyl chloride }, \mathrm{Cl}_{2}}=1.06$ and for $\mathrm{ECH}$ in the chlorohydrination step $\xi_{\mathrm{ECH}, \mathrm{Cl}_{2}}=0.77$. The value for allyl chloride considers a chlorine conversion of $86 \%$ [43].

\subsection{Chloromethanes}

We consider the direct chlorination of methyl chloride with hydrogen chloride as byproduct (see section 3). The reaction is exothermic and the resulting mixture always consists of all three chloromethanes. Their ratio is determined by kinetic parameters and the ratio of chlorine to methyl chloride [67].

$$
\begin{array}{r}
\mathrm{CH}_{3} \mathrm{Cl}+\mathrm{Cl}_{2} \longrightarrow \mathrm{CH}_{2} \mathrm{Cl}_{2}+\mathrm{HCl} \\
\mathrm{CH}_{2} \mathrm{Cl}_{2}+\mathrm{Cl}_{2} \longrightarrow \mathrm{CHCl}_{3}+\mathrm{HCl} \\
\mathrm{CHCl}_{3}+\mathrm{Cl}_{2} \longrightarrow \mathrm{CCl}_{4}+\mathrm{HCl}
\end{array}
$$

\section{Process description}

Fig. 8 shows the chloromethane process and relevant process parameters. The process has a relatively simple design with a high product selectivity [33]. The reactor temperature is primarily controlled by the chlorine feed and partially by preheating methyl chloride [47. A constant reactor temperature in the range from $350{ }^{\circ} \mathrm{C}$ to $550{ }^{\circ} \mathrm{C}$ [47] is important for two reasons: Firstly, the ignition temperature of the reaction lies between $250^{\circ} \mathrm{C}$ to $270{ }^{\circ} \mathrm{C}[33$; secondly, chloromethanes decompose above $550{ }^{\circ} \mathrm{C}$ [47. Producers and customers prefer certain chloromethanes, normally dichloromethane [33]. Hence, variations in the composition may lead to lower revenues. The composition is controlled by the ratio of chlorine to 


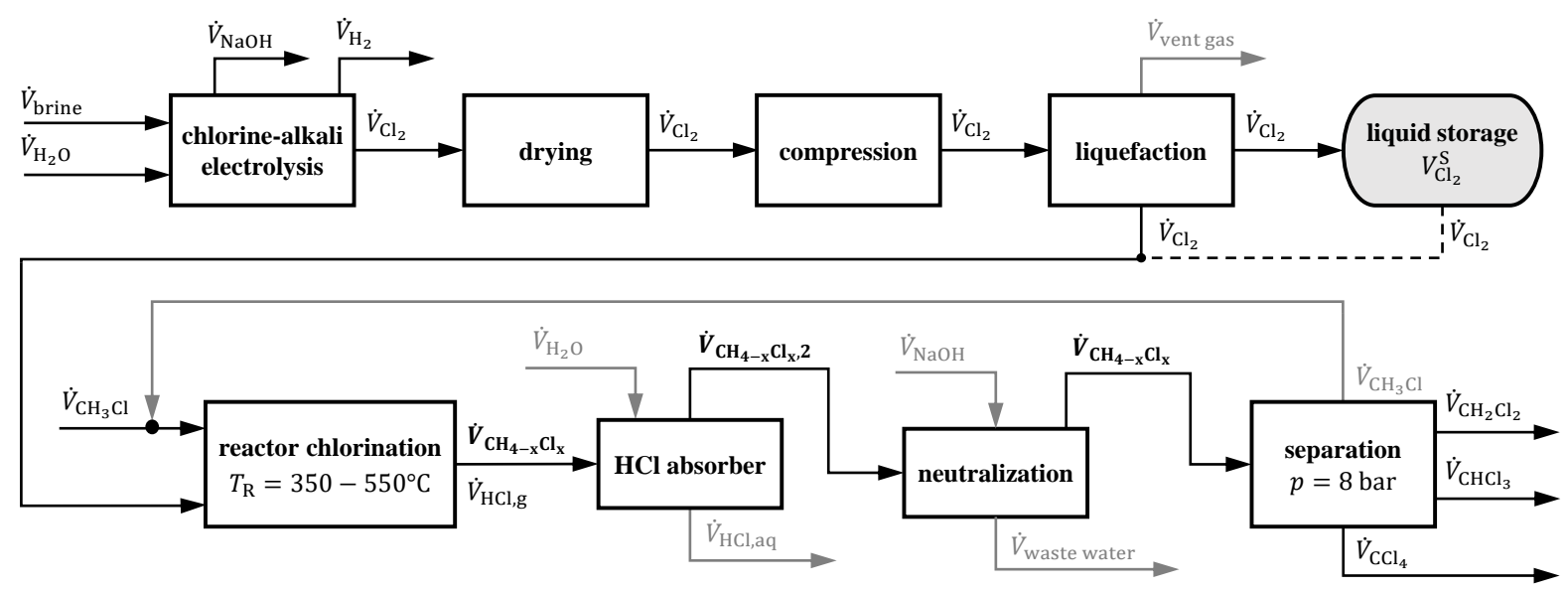

Figure 8: Simplified flow chart of the chloromethane process, based on [33, 47].

methyl chloride [47]. The lower the proportion of chlorine, the higher is the proportion of dichloromethane in the product mix. In the opposite case, the proportions of tri- and tetrachloromethane rise in in the product mix [67].

\section{Storage}

Chloromethanes are liquid at ambient temperature and well storable in vessels of iron and steel. They also require dry conditions as water promotes decomposition [47]. Dichloromethane should be protected from direct sunlight due to its low normal boiling point.

\section{Flexibility categorisation}

The product yield and reactor temperature are affected by a fluctuating chlorine feed. The product yield relates in this process to the preferred product composition. The reduction of the chlorine quantity would lead to a decreasing reactor temperature and to an increased proportion of dichloromethane. Conversely, the temperature and the proportion of higher chlorinated chloromethanes would rise if the chlorine quantity increased. Besides, the limits of load changes are defined by the minimal and maximal temperature of $350{ }^{\circ} \mathrm{C}$ and $550{ }^{\circ} \mathrm{C}$. Adjusting the methyl chloride quantity to the chlorine quantity could be one solution to provide flexibility. The temperature could be stabilised by controlling the preheating temperature of methyl chloride. The application of an inert gas could also be a solution for controlling the temperature and the composition of the product in case of load increase. Nitrogen and hydrogen chloride are already applied in practice as inert gases [47]. The storage of chloromethanes is realisable with moderate requirements.

In summary, the chloromethanes process is classified into the flexibility category B. Due to the fact that product yields of the three chloromethanes as well as the reactor temperature are influenced by the chlorine feed, the flexibilisation requires manageable interventions, and adjustments are needed for the process control. 


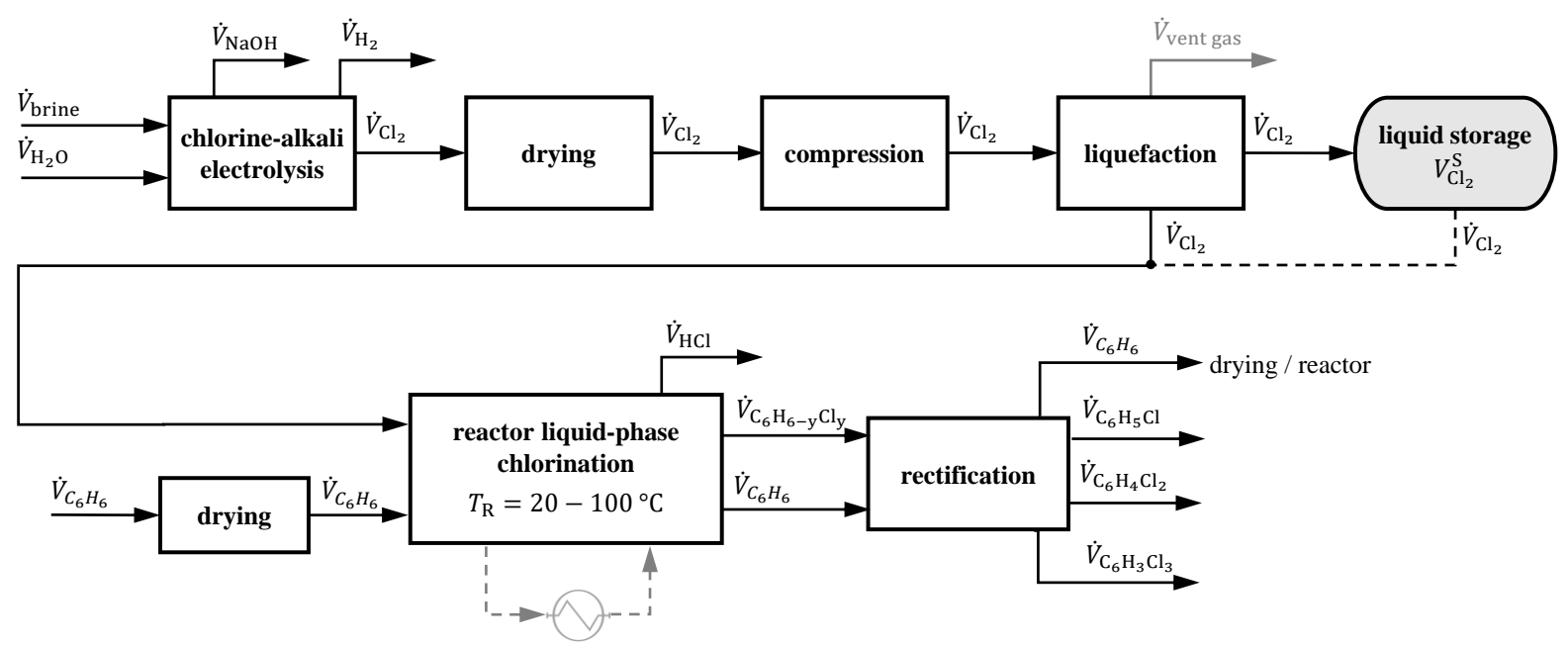

Figure 9: Simplified flow chart of the chlorobenzene process, based on [36, 68.

\subsection{Chlorobenzenes}

Chlorobenzenes are produced by direct chlorination of benzene in the liquid phase. Hydrogen chloride is formed as a by-product. The chlorination is exothermic [68]. The product is generally a mixture of isomers and compounds with varying degrees of chlorination [36].

$$
\begin{array}{r}
\mathrm{C}_{6} \mathrm{H}_{6}+\mathrm{Cl}_{2} \longrightarrow \mathrm{C}_{6} \mathrm{H}_{5} \mathrm{Cl}+\mathrm{HCl} \\
\mathrm{C}_{6} \mathrm{H}_{5} \mathrm{Cl}+\mathrm{Cl}_{2} \longrightarrow \mathrm{C}_{6} \mathrm{H}_{4} \mathrm{Cl}_{2}+\mathrm{HCl}
\end{array}
$$

\section{Process description}

Figure 9 describes the continuous process. The reaction is carried out in the presence of a catalyst, most commonly iron(III) chloride, at moderate temperature and atmospheric pressure [36]. The influence on the composition of the product is limited [68]. Important factors are reactor temperature, the catalyst, and particularly the ratio of chlorine to benzene at the beginning of the reaction [36]. However, not only the temperature at the beginning affects the composition, but also the temperature profiles during the reaction. Continuous processes need a good control of the reactor temperature, a suitable residence spectrum and intensive mixing, this favors high selectivity [36]. Because monochlorobenzene and dichlorobenzenes are preferred by the market, the regulation of the product composition is of great economic importance [36]. The hazard potential increases when the chlorine concentration builds up in the reactor, which can result in spontaneous combustion 68.

\section{Flexibility categorisation}

Flexibilisation has negative effects on the product yield, in this context on the preferred product composition, and the reactor temperature. Product yield also depends significantly on reactor temperature. Both criteria are highly influenced by the proportion of chlorine. This implies that small changes in chlorine quantity could lead to a variation of the product 


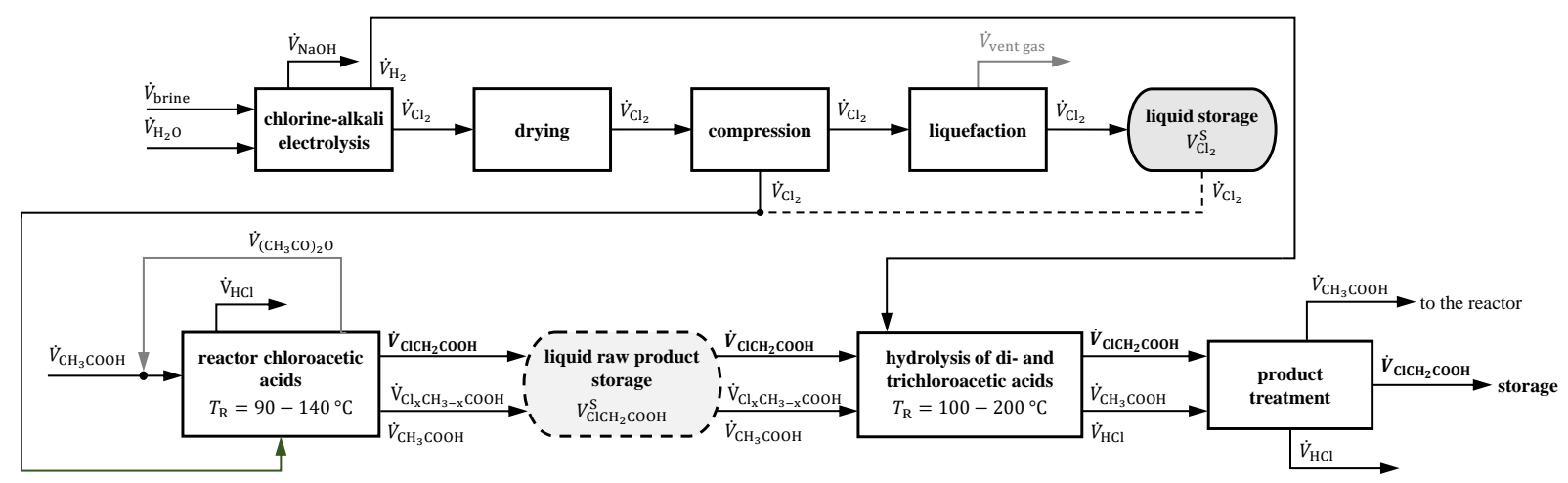

Figure 10: Simplified flow chart of the chloroacetic acid process, based on 69.

composition. Consequently, flexibilisation, especially in the case with a higher chlorine quantity, would lead to a lower product yield. Furthermore, an increasing chlorine flow increases the hazard potential of a spontaneous combustion. Due to this, flexibilisation is not possible and the chlorobenzenes process is assigned to the flexibility category D.

\subsection{Chloroacetic acid}

Chloroacetic acid is formed in a multistage reaction with the interim-products acetic anhydride and acetyl chloride [69]. The reaction can be described as follows:

$$
\mathrm{CH}_{3} \mathrm{COOH}+\mathrm{Cl}_{2} \longrightarrow \mathrm{ClCH}_{2} \mathrm{COOH}+\mathrm{HCl}
$$

\section{Process description}

Acetic acid is mixed with the recycled interim-product acetic anhydride and is fed into the reactor 69. The mixture is chlorinated in the liquid phase at $100^{\circ} \mathrm{C}$ to $110{ }^{\circ} \mathrm{C}[70$ or $90{ }^{\circ} \mathrm{C}$ to $140^{\circ} \mathrm{C}$ [69]. By-products are di- and trichloroacetic acid [69], which are formed mainly in the gas phase [71]. The chlorine feed is controlled to minimise the amount of chlorine in the gas phase [69]. The di- and trichloroacetic acid are dechlorinated by catalytic hydrogenation to form chloroacetic acid or acetic acid in a downstream reactor [72]. There is no information available concerning the temperature control. Acetic acid is preheated before being fed into the reactor [73, 70]. The process for acetic acid production is shown in Fig. 10 .

\section{Storage}

Chloroacetic acid is liquid at ambient temperature, the normal boiling point is $50.2^{\circ} \mathrm{C}[74$. It is highly toxic, flammable, and very reactive with water and many alkalies [74]. Because of their corrosivity, mono, di- , and trichloroacetic acid require ceramic-lined or lead-coated steel tanks for storage [69]. They can be stored for a long period under cool, dry conditions [69]. 
Table 3: Summary of the flexibility categorisations. An X marks the criterion that is responsible for the categorisation of the process.

\begin{tabular}{ccccc}
\hline Product & Category & Yield & Temperature & Storage \\
\hline DCE & $\mathrm{A}$ & & & \\
Phosgene & $\mathrm{D}$ & & & $\mathrm{X}$ \\
Diisocyanate & $\mathrm{C}$ & $\mathrm{X}$ & & \\
Polycarbonate & $\mathrm{D}$ & $\mathrm{X}$ & & \\
Propylene oxide & $\mathrm{C}$ & $\mathrm{X}$ & & \\
Allyl chloride & $\mathrm{B}$ & $\mathrm{X}$ & $\mathrm{X}$ & \\
ECH & $\mathrm{C}$ & $\mathrm{X}$ & & \\
Chloromethanes & $\mathrm{B}$ & $\mathrm{X}$ & $\mathrm{X}$ & \\
Chlorobenzenes & $\mathrm{D}$ & $\mathrm{X}$ & $\mathrm{X}$ & \\
CA & $\mathrm{A}$ & & & \\
\hline
\end{tabular}

\section{Flexibility categorisation}

Regarding the product yield, a flexibilisation is possible. The reaction is stable, although the reaction mechanism is complex. An obstacle is that an increased chlorine feed could be accompanied with an increasing ratio of chlorine in the gas phase and therefore an increase in the by-products yield. However, this effect could be minimized by adjusting the acetic acid feed relative to the chlorine feed. A marginal increase of the by-products could be compensated in the downstream hydrogenation process. Chloroacetic acid and the by-products are storable in an acid-resistant container. It was assumed that the fluctuating chlorine feed has no effect on the reactor temperature, because there is no information about this effect. An intermediate storage could decouple the hydrogenation process from fluctuations and could avoid bottlenecks in the downstream processes. As the effects of flexibilisation on product yield are negligible and the product is storable if safety requirements are fulfilled, the chloroacetic acid process is grouped in the flexibility category A.

\subsection{Summary of process analysis}

Tab. 3 presents the summary of the flexibility categorisation. It shows that the yield decreases are the most important reason why flexibilisation is hard to achieve for the investigated processes.

\section{Results}

The results for the relevant processes of the chlorine value chain are shown in Table 4 . Based on these values for the specific electricity demand of each process, the available positive DR (load reduction) potential for each category is estimated using Eq. (6). The ECH process can be separated into the allyl chloride step, which is allocated to the category $\mathrm{B}$, and the chlorohydrination step for which the unfavorable case category $\mathrm{C}$ is presumed. The results are shown in Fig. 11. Category D is not included in the diagram because processes of this category cannot provide DR potential. 
Table 4 and Fig. 11 show that the DR potentials and their availability differ for each subsequent chlorine process. The DCE process with a potential of $113 \mathrm{MW}$ is of greatest importance for flexibilisation. Firstly, flexibilisation could be implemented with minor adjustments (category A). Secondly, DCE is of economic importance and has a high production capacity in Germany with a corresponding chlorine demand. However, propylene oxide and diisocyanate, also subsequent products with a high production capacity, have a minor importance for the DR potentials of the chloralkali process because of the obstacles for flexibilisation. Despite high flexibility potentials, chloroacetic acid has also a low relevance for the overall DR potentials of the chloralkali process due to the small production capacity. The same applies to allyl chloride and chloromethanes, which are grouped in the flexibility category B.

The results for the specific electrical energy in Table 4 show that propylene oxide and especially epichlorohydrin have by far the highest values. The reason is the high demand on chlorine of this processes.

Based on our analysis of the chloralkali process, we summarize the results as follows:

- $33 \%$ of the overall DR potential are realisable without any constraints as the subsequent processes can operate with a flexible chlorine feed and intermediates can be stored easily. These DR potentials are easy to implement and have low costs.

- $12 \%$ of the overall DR potential are realisable but require adjustments in the process control to implement flexible chlorine feed or increased safety provisions for the product storage involving additional costs. These requirements are also connected with costs for realising the DR potentials.

- $49 \%$ of the overall DR potential have strong limitations. They are sensitive with respect to the chlorine feed, which leads to potentially hazardous operation or a decline in product quality. This requires many adjustments of the process control. In addition, storing intermediates might be difficult. These processes have the highest cost to implement DR.

- $6 \%$ of the overall DR potential are not realisable, because the subsequent chlorine processes cannot operate flexibly. Hence, no storage capacity is available.

\section{Conclusion}

If the chloralkali process shall be used for flexible operation and demand response, not only the electrolyser but also the subsequent processes must be operated flexibly. For this purpose, we analysed these subsequent processes in terms of their flexibility towards fluctuations in the chlorine feed. First of all, the more than 40 subsequent products were narrowed down to those with an overall chlorine demand of at least $2 \%$ in Germany. We identified the eight relevant subsequent process 1,2-dichloroethane, diisocyanate (MDI and TDI), polycarbonate, propylene oxide, epichlorohydrin, chloromethane, chlorinated benzenes and chloroacetic acid, with decreasing order of the overall chlorine demand. These processes consume $68 \%$ of the 
Table 4: Results of the flexibility analysis for the relevant process of the chlorine value chain for Germany.

\begin{tabular}{|c|c|c|c|c|}
\hline Product $^{\mathrm{a}} i$ & $\begin{array}{c}\text { Flexibility } \\
\text { category }\end{array}$ & $\begin{array}{l}\text { Annual demand } \\
\text { of chlorine }{ }^{\mathrm{b}} m_{\mathrm{Cl}_{2}, i}^{\mathrm{a}} \\
\text { in } \mathrm{kt} \mathrm{a}^{-1}\end{array}$ & $\begin{array}{c}\text { Annual electricity } \\
\text { demand }^{\mathrm{b}} W_{\mathrm{el}, i}^{\mathrm{a}} \\
\text { in } \mathrm{GWh} \mathrm{a}^{-1}\end{array}$ & $\begin{array}{c}\text { Specific electrical } \\
\text { energy } \mu_{\mathrm{el}, i} \\
\text { in } \mathrm{kWh} \mathrm{kg}^{-1}{ }_{i}\end{array}$ \\
\hline DCE & $\mathrm{A}$ & 806 & 2079 & $1.86^{\mathrm{c}}$ \\
\hline Diisocyanate & $\mathrm{C}$ & 630 & 1622 & $1.69^{\mathrm{d}}$ \\
\hline Polycarbonate & $\mathrm{D}$ & 80 & 205 & 0.72 \\
\hline $\begin{array}{l}\text { Propylene ox- } \\
\text { ide }\end{array}$ & $\mathrm{C}$ & 507 & 1307 & 3.43 \\
\hline $\mathrm{ECH}$ & $\mathrm{B}-\mathrm{C}$ & 349 & 901 & 4.23 \\
\hline $\begin{array}{l}\text { Chloro- } \\
\text { methanes }\end{array}$ & B & 129 & 332 & $2.55^{\mathrm{d}}$ \\
\hline $\begin{array}{l}\text { Chloro- } \\
\text { benzenes }\end{array}$ & $\mathrm{D}$ & 79.2 & 204 & $1.86^{\mathrm{d}}$ \\
\hline $\mathrm{CA}$ & A & 78.8 & 203 & 1.94 \\
\hline
\end{tabular}

a DCE - 1,2-Dichloroethane, Diisocyanate includes MDI and TDI, ECH - Epichlorohydrin, CA Chloroacetic acid

b Values for Germany

c With $\xi_{\mathrm{Cl}_{2}, i}=0.72$, calculated by the mass balance of the direct chlorination.

$\mathrm{d}$ Averaged value based on the production quantity of the single products; for diisocyanate: MDI and TDI, for chloromethanes: $\mathrm{CH}_{2} \mathrm{Cl}_{2}, \mathrm{CHCl}_{3}$, and $\mathrm{Cl}_{4}$; for chlorobenzenes: $\mathrm{C}_{6} \mathrm{H}_{5} \mathrm{Cl}$ and $\mathrm{C}_{6} \mathrm{H}_{4} \mathrm{Cl}_{2}$

total chlorine production in Germany. Secondly, we analyzed these relevant processes in more detail based on available information from the literature regarding their current design and their requirements for safe process operation and their potential for storing intermediates. For this purpose, flexibility categories were defined based on specific criteria, such as sensitivity with respect to fluctuating feeds or the storability of intermediates.

We found that 1,2-dichloroethane and chloroacetic acid have the highest flexibility potential (category A). The chloromethane process and allyl chloride, an intermediate of epichlorohydrin, require adjustments of the control scheme and are assigned to category B. A limited flexibility (category $\mathrm{C}$ ) was identified for the diisocyanate, the propylene oxide, and the chlorohydrination step of epichlorohydrin. These processes need considerable adjustments in the control scheme or require high precautions for storing intermediates. Flexibilisation is not viable (category D) for polycarbonate and chlorinated benzenes. Based on these results, $33 \%$ of the overall demand response potential can be implemented without any limitations, $12 \%$ requires adjustments in the process control to implement and realise flexible operation. The demand response potentials of $49 \%$ are strongly limited and of $6 \%$ are not realisable due to process restrictions. In particular, the DCE process is of great importance because it has a high production capacity and a high flexibility potential.

In further research, the subsequent processes, which were assigned to categories A and B, should be analysed in more detail. We will develop dispatch models for the CAE including 


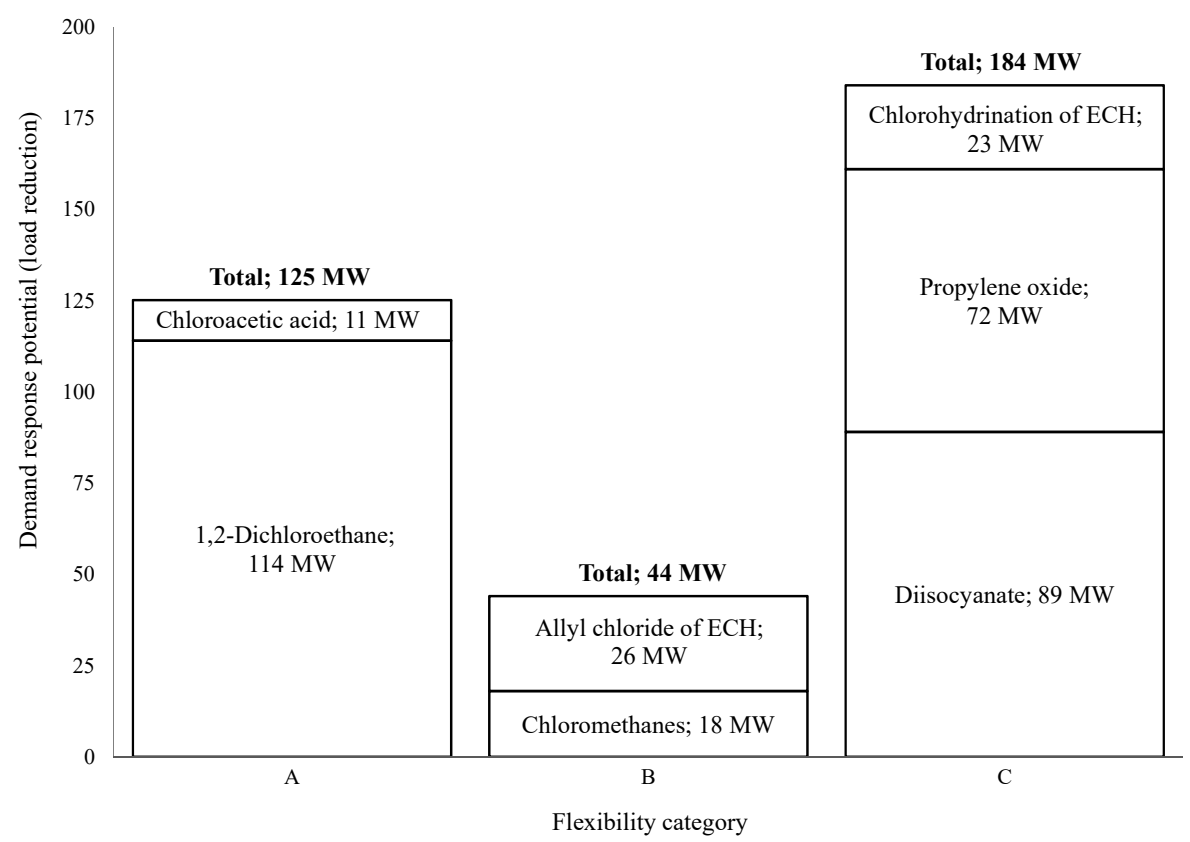

Figure 11: Demand response potential for load reduction of each flexibility category.

these value chains. A result should be the economic operation of the chemical plants regarding different products of the electricity markets. The overall mission is to determine the feasible demand response potentials. Because our study only yields qualitative results, this needs to be confirmed by a more rigorous approach using dynamic simulations of these processes in the first step. In addition, the economic feasibility should be looked at more closely. Here we did not consider yet investment expenditures and operating costs necessary for flexibilisation and compare them to the financial benefits of offering operating reserve but focused on the process-specific aspects first.

\section{Acknowledgements}

The authors gratefully acknowledge the financial support of the German Federal Ministry of Economic Affairs and Energy for the project ChemEFlex (project number 0350013A). The ChemEFlex project is concerned with the technically feasible demand response potential of the electrochemical industry, more specifically of chloralkali electrolysis. This multidisciplinary research project investigates the challenges for flexibilisation with partners from industry. 


\section{Nomenclature}

\section{Latin symbols}

$e_{\mathrm{el}, \mathrm{Cl}_{2}} \quad$ Specific electrical energy consumption of chlorine, $\mathrm{Wh}_{\mathrm{el}} \mathrm{g}_{\mathrm{Cl}_{2}}^{-1}$

$m \quad$ Mass, $\mathrm{g}$

$m_{i}^{\mathrm{a}} \quad$ Annual produced mass of product $i, \mathrm{~g} \mathrm{a}^{-1}$

$m_{\mathrm{Cl}_{2}}^{\mathrm{a}} \quad$ Annual produced mass of chlorine, $\mathrm{g} \mathrm{a}^{-1}$

$m_{\mathrm{Cl}_{2}, i}^{\mathrm{a}} \quad$ Annual demand chlorine mass for product $i, \mathrm{~g} \mathrm{a}^{-1}$

$P_{\mathrm{DR}, i} \quad$ Potential of load reduction for product $i, \mathrm{~W}_{\mathrm{el}}$

$p \quad$ Pressure, bar

$S_{\mathrm{x}} \quad$ Selectivity to the product $i, \%$

$s_{\mathrm{DR}} \quad$ Demand response proportion, $\%$

$T_{\mathrm{R}} \quad$ Reactor temperature, ${ }^{\circ} \mathrm{C}$

$t_{\mathrm{fl}} \quad$ Operation hours per year at full load, $\mathrm{h}$

$V^{\mathrm{s}} \quad$ Storage capacity, $\mathrm{m}^{3}$

$\dot{V} \quad$ Volumetric flow rate, $\mathrm{m}^{3} \mathrm{~s}^{-1}$

$X_{j} \quad$ Conversion of educt $j, \%$

$x_{\mathrm{Cl}_{2}, i} \quad$ Proportion of the product $i$ of the overall chlorine demand, $\%$

$Y_{\mathrm{i}} \quad$ Yield of product $i, \%$

$W_{\mathrm{el}, i}^{\mathrm{a}} \quad$ Annual electricity demand for product $i \mathrm{Wh} \mathrm{a}^{-1}$

$w \quad$ Mass fraction, $\%$

\section{Greek symbols}

$\epsilon_{j} \quad$ Excess of educt $j, \%$

$\xi_{\mathrm{Cl}_{2}, i} \quad$ Chlorine demand in g per product mass $i, \mathrm{~g}_{\mathrm{Cl}_{2}} \mathrm{~g}_{i}^{-1}$

$\mu_{\mathrm{el}, i} \quad$ Specific electrical energy per product mass $i, \mathrm{Whg}^{-1}$

$\tau \quad$ Retention time, $\mathrm{s}$

\section{References}

[1] J. Torriti, M. G. Hassan, M. Leach, Demand response experience in Europe: Policies, programmes and implementation, Energy 35 (4) (2010) 1575-1583. doi:10.1016/j.energy.2009.05.021.

[2] P. Finn, C. Fitzpatrick, Demand side management of industrial electricity consumption: Promoting the use of renewable energy through real-time pricing, Applied Energy 113 (2014) 11-21. doi:10.1016/j apenergy.2013.07.003

[3] A. S. Brouwer, M. van den Broek, W. Zappa, W. C. Turkenburg, A. Faaij, Least-cost options for integrating intermittent renewables in low-carbon power systems, Applied Energy 161 (2016) 48-74. doi:10.1016/J.APENERGY.2015.09.090.

[4] H. C. Gils, Economic potential for future demand response in germany - modeling approach and case study, Applied Energy 162 (2016) 401-415. doi:10.1016/j.apenergy.2015.10.083.

[5] N. O'Connell, P. Pinson, H. Madsen, M. O'Malley, Benefits and challenges of electrical demand response: A critical review, Renewable and Sustainable Energy Reviews 39 (2014) 686-699. doi: 10.1016/j.rser.2014.07.098

[6] U.S. Department of Energy, Benefits of demand response in electricity markets and recommendations for achieving them, Report to the United States Congress, Washington (2006). 
[7] P. D. Lund, J. Lindgren, J. Mikkola, J. Salpakari, Review of energy system flexibility measures to enable high levels of variable renewable electricity, Renewable and Sustainable Energy Reviews 45 (2015) 785-807. doi:10.1016/j.rser.2015.01.057.

[8] J. Aghaei, M.-I. Alizadeh, Demand response in smart electricity grids equipped with renewable energy sources: A review, Renewable and Sustainable Energy Reviews 18 (2013) 64-72. doi:10.1016/j.rser 2012.09.019.

[9] F. Ausfelder, A. Seitz, S. von Roon (Eds.), Flexibilitätsoptionen in der Grundstoffindustrie, Report commissioned by Federal Ministry of Education and Research, [in German], Frankfurt am Main, 2018.

[10] Deutsche Energie-Agentur GmbH (dena), dena-Netzstudie II - Integration erneuerbarer Energien in die deutsche Stromversorgung im Zeitraum 2015-2020 mit Ausblick auf 2025, Report [in German], Berlin (2010).

[11] H. C. Gils, Assessment of the theoretical demand response potential in Europe, Energy 67 (2014) 1-18. doi:10.1016/j.energy.2014.02.019.

[12] M. Paulus, F. Borggrefe, The potential of demand-side management in energy-intensive industries for electricity markets in Germany, Applied Energy 88 (2) (2011) 432-441. doi:10.1016/j.apenergy 2010.03.017.

[13] F. Klaucke, T. Karsten, F. Holtrup, E. Esche, T. Morosuk, G. Tsatsaronis, J.-U. Repke, Demand Response Potenziale in der chemischen Industrie, Chemie Ingenieur Technik 89 (9) (2017) 1133-1141, [in German]. doi:10.1002/cite.201600073.

[14] T. O'Brien, T. V. Bommaraju, F. Hine, Handbook of Chlor-Alkali Technology, Springer, Boston, 2005. doi:10.1007/b113786.

[15] Euro Chlor, Chlor-alkali industry review 2018/2019 (2019). URL https://chlorineindustryreview.com/

[16] T. V. Bommaraju, B. Lüke, T. F. O'Brien, M. C. Blackburn, Chlorine, in: Kirk-Othmer Encyclopedia of Chemical Technology, J. Wiley, Hoboken, 2002, pp. 130-211. doi:10.1002/0471238961. 0308121503211812.a01.pub2.

[17] P. Schmittinger, T. Florkiewicz, L. C. Curlin, B. Lüke, R. Scannell, T. Navin, E. Zelfel, R. Bartsch, Chlorine, in: Ullmann's Encyclopedia of Industrial Chemistry, Wiley-VCH, Weinheim, 2012. doi: 10.1002/14356007.a06_399.pub3

[18] T. A. Ryan, C. Ryan, E. A. Seddon, K. R. Seddon (Eds.), Phosgene and Related Carbonyl Halides, Vol. 24 of Topics in Inorganic and General Chemistry, Elsevier, Amsterdam, 1996.

[19] T. Brinkmann, G. Giner Santonja, L. Delgado Sancho, F. Schorcht, S. Roudier, Best available techniques (bat) reference document for the production of chlor-alkali, Report EUR 26844 EN, Luxembourg (2014). doi:10.2791/13138

[20] S. Campanari, G. Guandalini, J. Coolegem, J. ten Have, P. Hayes, A. H. Pichel, Modeling, Development, and Testing of a 2 MW Polymeric Electrolyte Membrane Fuel Cell Plant Fueled With Hydrogen From a Chlor-Alkali Industry, Journal of Electrochemical Energy Conversion and Storage 16 (4). doi:10.1115/1.4042923

[21] Euro Chlor, Products of the chlorine tree (2017). URL https://www . eurochlor.org/the-chlorine-tree/

[22] C. Kurt, J. Bittner, Sodium hydroxide, in: Ullmann's Encyclopedia of Industrial Chemistry, Wiley-VCH, Weinheim, 2012. doi:10.1002/14356007.a24_345.pub2

[23] T. Budiarto, E. Esche, J. U. Repke, E. Leksono, Dynamic model of chloralkali membrane process, Procedia Engineering 170 (2017) 473-481. doi:10.1016/j.proeng.2017.03.076

[24] J. I. Otashu, M. Baldea, Demand response-oriented dynamic modeling and operational optimization of membrane-based chlor-alkali plants, Computers \& Chemical Engineering 121 (2019) 396-408. doi: 10.1016/j.compchemeng.2018.08.030.

[25] J. I. Otashu, M. Baldea, Scheduling chemical processes for frequency regulation, Applied Energy 260 (2020) 114125. doi:10.1016/j.apenergy.2019.114125.

[26] L. C. Brée, K. Perrey, A. Bulan, A. Mitsos, Demand side management and operational mode switching in chlorine production, AIChE Journal 65 (7) (2018) e16352. doi:10.1002/aic.16352 
[27] K. Roh, L. C. Brée, K. Perrey, A. Bulan, A. Mitsos, Flexible operation of switchable chlor-alkali electrolysis for demand side management, Applied Energy 255 (2019) 113880. doi:10.1016/j . apenergy 2019.113880

[28] R. E. Swaney, I. E. Grossmann, An index for operational flexibility in chemical process design. Part I: Formulation and theory, AIChE Journal 31 (4) (1985) 621-630. doi:10.1002/aic.690310412.

[29] R. E. Swaney, I. E. Grossmann, An index for operational flexibility in chemical process design. Part II: Computational algorithms, AIChE Journal 31 (4) (1985) 631-641. doi:10.1002/aic.690310413.

[30] D. C. H. Chien, P. L. Douglas, A. Penlidis, A method for flexibility analysis of continuous processing plants, The Canadian Journal of Chemical Engineering 69 (1) (1991) 58-66. doi:10.1002/cjce 5450690107.

[31] S. Mitra, I. E. Grossmann, J. M. Pinto, N. Arora, Optimal production planning under time-sensitive electricity prices for continuous power-intensive processes, Computers \& Chemical Engineering 38 (2012) 171-184. doi:10.1016/j.compchemeng.2011.09.019

[32] Verband der Chemischen Industrie e. V. (VCI), Chemiewirtschaft in Zahlen 2017, Report [in German], Frankfurt am Main (2017).

URL https://www.vci.de/vci/downloads-vci/publikation/chiz-historisch/ chemiewirtschaft-in-zahlen-2017.pdf

[33] H.-J. Arpe, Industrielle organische Chemie: Bedeutende Vor- und Zwischenprodukte, 6th Edition, Wiley-VCH, Weinheim, 2007.

[34] Statistisches Bundesamt, Produktionswert, -menge, -gewicht und Unternehmen der Vierteljhrlichen Produktionserhebung, Table 42131-0003 [in German] (2017).

URL https://www-genesis.destatis.de/

[35] M. Peters, A. Ahrens, Auswirkungen des REACH-Verfahrens auf die Herstellung von Epichlorhydrin sowie die Anwendung seiner Folgeprodukte als Kleber in der Automobilindustrie: Untersuchungsbericht Stand: April 2006, [in German] (2016).

URL https://www.umwelt.niedersachsen.de/download/6355/Bericht_mit_

Schlussfolgerungen_Auswirkungen_des_REACH-Verfahrens_auf_die_Herstellung_von_

Epichlorhydrin_sowie_die_Anwendung_seiner_Folgeprodukte_als_Kleber_in_der_ Automobilindustrie_Mai_2006_.pdf

[36] U. Beck, E. Löser, Chlorinated benzenes and other nucleus-chlorinated aromatic hydrocarbons, in: Ullmann's Encyclopedia of Industrial Chemistry, Wiley-VCH, Weinheim, 2012. doi:10.1002/14356007 $006 \_003$.

[37] E. Langer, H. Rassaerts, P. Kleinschmidt, T. R. Torkelson, K. K. Beutel, Chlor opropanes, chlorobutanes, and chlorobutenes, in: Ullmann's Encyclopedia of Industrial Chemistry, Wiley-VCH, Weinheim, 2012. doi:10.1002/14356007.007_o01.

[38] European Commission, Reference document on best available techniques for the production of speciality inorganic chemicals, Report BREF 0907, Brussels (2007).

URL https://eippcb.jrc.ec.europa.eu/reference/BREF/sic_bref_0907.pdf

[39] Bundesanstalt für Geowissenschaften und Rohstoffe, Rohstoffwirtschaftliche Steckbriefe - Phosphat, Report [in German] (2014).

URL https://www.bgr.bund.de/DE/Themen/Min_rohstoffe/Downloads/rohstoffsteckbrief_ phosphat2014.pdf

[40] H. Baer, M. Bergamo, A. Forlin, L. H. Pottenger, J. Lindner, Propylene oxide, in: Ullmann's Encyclopedia of Industrial Chemistry, Wiley-VCH, Weinheim, 2012. doi:10.1002/14356007.a22_239.pub3.

[41] M. Bernhard, J. Anton, F. Schmidt, F. Sandkaulen, M. Pascaly, Uber den Technologiewandel in der Propylenoxid-Herstellung, Chemie in unserer Zeit 51 (3) (2017) 198-209, [in German]. doi: 10.1002/ciuz.201700764.

[42] G. Abts, T. Eckel, R. Wehrmann, Polycarbonates, in: Ullmann's Encyclopedia of Industrial Chemistry, Wiley-VCH, Weinheim, 2014. doi:10.1002/14356007.a21_207.pub2.

[43] L. Krähling, J. Krey, G. Jakobson, J. Grolig, L. Miksche, Allyl compounds, in: Ullmann's Encyclopedia of Industrial Chemistry, Wiley-VCH, Weinheim, 2012. doi:10.1002/14356007.a01_425. 
[44] H. Vogt, J. Balej, J. E. Bennett, P. Wintzer, S. Akbar Sheikh, P. Gallone, S. Vasudevan, K. Pelin, Chlorine oxides and chlorine oxygen acids, in: Ullmann's Encyclopedia of Industrial Chemistry, Wiley-VCH, Weinheim, 2010. doi:10.1002/14356007.a06_483.pub2.

[45] E.-L. Dreher, K. K. Beutel, J. D. Myers, T. Lübbe, S. Krieger, L. H. Pottenger, Chloroethanes and chloroethylenes, in: Ullmann's Encyclopedia of Industrial Chemistry, Wiley-VCH, Weinheim, 2014. doi:10.1002/14356007.006_o01.pub2.

[46] M. W. M. Hisham, T. V. Bommaraju, updated by Staff, Hydrogen chloride, in: Kirk-Othmer Encyclopedia of Chemical Technology, J. Wiley, Hoboken, 2014. doi:10.1002/0471238961.0825041808091908 a01.pub3.

[47] M. Rossberg, W. Lendle, G. Pfleiderer, A. Tögel, T. R. Torkelson, K. K. Beutel, Chloromethanes, in: Ullmann's Encyclopedia of Industrial Chemistry, Wiley-VCH, Weinheim, 2012. doi:10.1002/14356007. a06_233.pub3.

[48] Anonymous, 1,2-Dichlorethan, in: The MAK-Collection for Occupational Health and Safety, 2003, [in German]. doi:10.1002/3527600418.mb10706d0037.

[49] W. Schneider, W. Diller, Phosgene, in: Ullmann's Encyclopedia of Industrial Chemistry, Wiley-VCH, Weinheim, 2012. doi:10.1002/14356007.a19_411.

[50] K. L. Dunlap, Phosgene, in: Kirk-Othmer Encyclopedia of Chemical Technology, J. Wiley, Hoboken, 2010. doi:10.1002/0471238961.1608151904211412.a01.pub3.

[51] G. Oertel (Ed.), Polyurethane, 2nd Edition, Vol. 7 of Kunststoff-Handbuch, Hanser, Munich, 1983, [in German].

[52] C. Six, F. Richter, Isocyanates, organic, in: Ullmann's Encyclopedia of Industrial Chemistry, Wiley-VCH, Weinheim, 2012. doi:10.1002/14356007.a14_611.

[53] W. Adam, Organische Technologie: 2, 4th Edition, Vol. 6 of Chemische Technologie, Hanser, Munich, 2004, [in German].

[54] R. Ohlinger, H. Schnez, L. Pfannenstiel, B. Blumenberg, H. J. Raabe, Verfahren zur kontinuierlichen Herstellung von organischen Mono- und/oder Polyisocyanaten, Patent DE 3403204 A1, BASF AG, [in German] (1985).

[55] R. H. Richter, R. d. Priester, Isocyanates, organic, in: Kirk-Othmer Encyclopedia of Chemical Technology, J. Wiley, Hoboken, 2000. doi:10.1002/0471238961.0919150318090308.a01.

[56] L. Bottenbruch (Ed.), Polycarbonate, Polyacetale, Polyester, Celluloseester, Vol. 3/1 of KunststoffHandbuch: Technische Thermoplaste, Hanser, Munich, 1992, [in German].

[57] G. Y. T. Liu, W. F. Richey, J. E. Betso, B. Hughes, J. Klapacz, J. Lindner, Chlorohydrins, in: Ullmann's Encyclopedia of Industrial Chemistry, Wiley-VCH, Weinheim, 2014. doi:10.1002/14356007.a06_565. pub2.

[58] W. F. Richey, Chlorohydrins, in: Kirk-Othmer Encyclopedia of Chemical Technology, J. Wiley, Hoboken, 2000. doi:10.1002/0471238961.0308121518090308.a01.

[59] J. Liu, X. Chen, D. Xue, X. Liu, J. Xue, F. Li, Z. Lv, Mechanism of chlorination process: From acetic acid to monochloroacetic acid and byproducts using acetic anhydride as catalyst, Revue Roumaine de Chimie 63 (3) (2018) 235-244.

[60] D. L. Trent, Propylene oxide, in: Kirk-Othmer Encyclopedia of Chemical Technology, J. Wiley, Hoboken, 2000. doi:10.1002/0471238961.1618151620180514.a01.pub2.

[61] B. M. Bell, J. R. Briggs, R. M. Campbell, S. M. Chambers, P. D. Gaarenstroom, J. G. Hippler, B. D. Hook, K. Kearns, J. M. Kenney, W. J. Kruper, D. J. Schreck, C. N. Theriault, C. P. Wolfe, Glycerin as a Renewable Feedstock for Epichlorohydrin Production. The GTE Process, Clean 36 (8) (2008) 657-661. doi:10.1002/clen.200800067

[62] I. C. Bikbulatov, J. P. Chlopotov, J. M. Japryncev, G. I. Kanaev, J. D. Morozov, R. Muchutdinov, L. A. Osin, M. V. Vagapov, Verfahren zur Herstellung von Glyzerin-Dichlorhydrin, Patent DE 000003437520 A1, [in German] (1986).

[63] C. Kneupper, L. Saathoff, Allyl chloride, in: Kirk-Othmer Encyclopedia of Chemical Technology, J. Wiley, Hoboken, 2000. doi:10.1002/0471238961.0112122511140521.a01. 
[64] G. Sienel, R. Rieth, K. T. Rowbottom, Epoxides, in: Ullmann's Encyclopedia of Industrial Chemistry, Wiley-VCH, Weinheim, 2012. doi:10.1002/14356007.a09_531.

[65] IPCS International Programme on Chemical Safety, Epichlorohydrin Health and Safety Guide No. 8 (1987).

URL http://www . inchem. org/documents/hsg/hsg/hsg008.htm

[66] J. E. Huber, J. Raushel, M. Hirsch, G. Zong, W. Shi, Epichlorohydrin, in: Encyclopedia of Reagents for Organic Synthesis, J. Wiley, Hoboken, 2001. doi:10.1002/047084289X.re005.pub3.

[67] B. E. Kurtz, Homogeneous kinetics of methyl chloride chlorination, Industrial \& Engineering Chemistry Process Design and Development 11 (3) (1972) 332-338. doi:10.1021/i260043a002.

[68] R. Krishnamurti, Chlorinated benzenes, in: Kirk-Othmer Encyclopedia of Chemical Technology, J. Wiley, Hoboken, 2000. doi:10.1002/0471238961.0308121502182501.a01.pub2.

[69] G. Koenig, E. Lohmar, N. Rupprich, M. Lison, A. Gnass, Chloroacetic acids, in: Ullmann's Encyclopedia of Industrial Chemistry, Wiley-VCH, Weinheim, 2012. doi:10.1002/14356007.a06_537.pub3.

[70] H. Schlecht, H. Albers, R. Oster, H. Schroeder, Verfahren zur Herstellung von Monochloressigsäure, Patent DE 000001224298 B, BASF AG, [in German] (1967).

[71] J.-W. Xue, J.-P. Zhang, B. Wu, F.-X. Li, Z.-P. Lv, Study on gas-phase mechanism of chloroacetic acid synthesis by catalysis and chlorination of acetic acid, Asian Journal of Chemistry 26 (2) (2014) 475-480. doi:10.14233/ajchem.2014.15484.

[72] M. Gescheidmeier, Verfahren zur kontinuierlichen Reinigung von roher Monochloressigsäure, Patent DE 000002323777 C2, Hoechst AG, [in German] (1975).

[73] W. Opitz, A. Jacobowsky, W. Burkhardt, H. Baader, Verfahren zur Herstellung von Monochloressigsäure, Patent DE 000001224298 B, Hoechst AG (1977).

[74] F. S. Wagner, Acetyl chloride, in: Kirk-Othmer Encyclopedia of Chemical Technology, J. Wiley, Hoboken, 2000. doi:10.1002/0471238961.0103052023010714.a04.pub2. 